\title{
DESLOCAMENTO MISCIVEL DA UREIA EM ALGUNS SOLOS DA REGIÃO AMAZÔNICA
}

REYNALDO LUIZ VICTÓRIA

Orientador: KLAUS REICHARDT

Tese apresentada à Escola Superior de Agricultura "Luiz de Queiroz", da Universidade de São Paulo, para obtenção do título de Doutor em Agronomia. Área de Concentração: Solos e Nutrição de Plantas.

\author{
PIRACICABA \\ Estado de São Paulo - Brasil \\ Novembro, 1980
}


A meus pais

OFEREÇO

A minha esposa Beatriz

e meu filho Daniel

DEDICO 


\section{AGRADECIMENTO ESPECIAL}

Ao Dr. Eiichi Matsui, modelo de dedicação ao trabalho e ponto de apoio firme e constante, pela amizade, sugestões e estímulo, imprescindíveis para a realização deste trabalho. 


\section{AGRADECIMENTOS}

- Ao Dr. Klaus Reichardt pela orientação e amizade;

- Aos amigos Dr. Paulo L. Libardi e Dr. Virgílio F. Nascimento Fe pelas sugestões e ajuda no desenvolvimento deste trabalho;

- Ao Dr. Eneas Salati pela minha iniciação científica;

- Aos Amigos Ricardo B. Sgrillo e Celso G. Furlan pela ajuda no desenvolvimento do programa de computador;

- Aos amigos José C. Araújo Silva, Sérgio Moraes, Marcelo C. Ulhoa, Segun do Urquiaga Caballero e Elias de Freitas Jr., pelo incentivo;

- Aos amigos Benedito H. Davanzo e Celso de Aguiar pela composição gräfica;

- A cara amiga Neusa Maria Augusti pelo serviço de datilografia;

- Aos técnicos Ademir Rodrigues e José Aurélio Bonassi pela ajuda nas aná lises químicas;

- A Seção de Química Analítica do CENA, pelo apoio nas anālises químicas; 
- Ao CENA pelas facilidades oferecidas;

- A FINEP e CNPq pelo apoio financeiro;

- A Cidá Cervellini, pelo incentivo;

- E a todos aqueles que, de uma maneira ou outra, contribuiram para a rea lização deste trabalho. 
INDICE

Pägina

RESUMO

xii

SUMMARY

xiv

1. INTRODUÇÃO

01

2. REVISAOO DA LITERATURA

03

2.1. Deslocamento miscível com solutos inertes e alimentação contínua

2.2. Deslocamento miscível de um pulso de soluto inerte...

2.3. Deslocamento miscível com o soluto sujeito a reações reversiveis

2.4. Deslocamento miscível com soluto sujeito a reações irreversĩveis

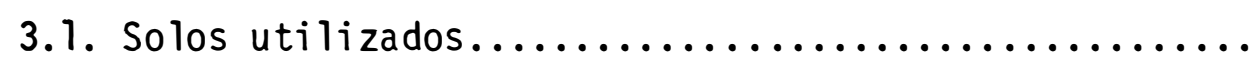

3.2. Arranjo experimental

3.3. Modelo matemático 


\section{LISTA DE TABELAS}

Página

Tabela 1. Características físicas e químicas dos solos utilizados

Tabela 2. Características experimentais de cada uma das 7 colunas utilizadas $\ldots \ldots \ldots \ldots \ldots \ldots \ldots \ldots \ldots \ldots \ldots \ldots$

Tabela 3. Recuperação de $C \ell^{-}$no efluente da coluna 1. Solo: Podzólico Vermelho-Amarelo

Tabela 4. Recuperação de uréia no efluente da coluna 1. Solo Podzölico Vermelho-Amarelo

Tabela 5. Recuperação de $C \ell^{-}$no efluente da coluna 2. Solo: Podzólico Vermelho Amarelo

Tabela 6. Recuperação de uréia no efluente da coluna 2. Solo:

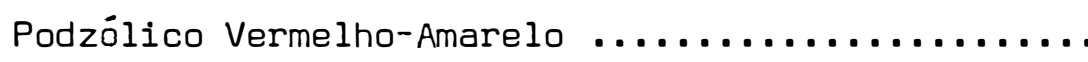

Tabela 7. Recuperação de $\mathrm{NH}_{4}^{+}-{ }^{15} \mathrm{~N}$ no efluente da coluna 3.So10: Podzólico Vermelho-Amarelo

Tabela 8. Distribuição e recuperação de $\mathrm{NH}_{4}^{+}-15 \mathrm{~N}$ trocável no solo da coluna 3. Solo:Podzólico Vermelho-Amarelo. 
Tabela 9. Distribuição e recuperação de ${ }^{15} \mathrm{~N}$ - orgânico no solo da coluna 3. Digestão de Kjeldhal após extração com

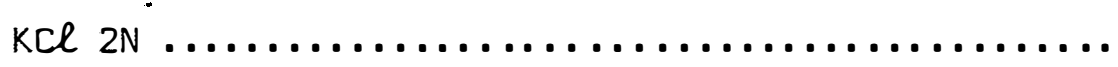

Tabela 10. Recuperação de $\mathrm{NH}_{4}^{+}-{ }^{15} \mathrm{~N}$ no efluente da coluna 4. So lo Latossolo Amarelo

Tabela 11. Distribuição e recuperação de $\mathrm{NH}_{4}^{+}-{ }^{15} \mathrm{~N}$ trocável pa ra o solo da coluna 4. Solo: Latossolo Amarelo ...

Tabela 12. Distribuição e recuperação de ${ }^{15} \mathrm{~N}$ orgânico no solo da coluna 4. Digestão de Kjeldhal após extração com KCl $2 \mathrm{~N}$

Tabela 13. Recuperação de uréia no efluente da coluna 5. Solo de vărzea

Tabela 14. Distribuição e recuperação de ${ }^{15} \mathrm{~N}$ no solo da coluna 5. Solo de vărzea $\ldots \ldots \ldots \ldots \ldots \ldots \ldots \ldots \ldots \ldots$

Tabela 15. Recuperação de uréia no efluente da coluna 6 . Solo de vărzea

Tabela 16. Distribuição e recuperação de ${ }^{15} \mathrm{~N}$ no solo da coluna 6. Solo de värzea 
Tabela 17. Recuperação de $\mathrm{NH}_{4}^{+}$no efluente da coluna 6. Solo



Tabela 18. Distribuição e recuperação de $\mathrm{NH}_{4}^{+}{ }^{15} \mathrm{~N}$ trocável (extração com KCl 2N) no solo da coluna 7. Solo de

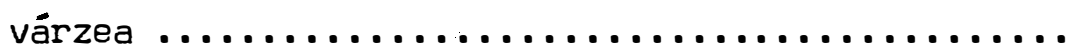

Tabela 19. Distribuição e recuperação de $N$ orgânico e ${ }^{15} \mathrm{~N}$ orgànico no solo da coluna 7. Digestão de Kjeldhal após extração com KCl 2N. Solo de várzea ........

Tabela 20. Recuperação de $\mathrm{NH}_{4}^{+}-15 \mathrm{~N}$ no efluente da coluna 7 . Solo de vărzea $\ldots \ldots \ldots \ldots \ldots \ldots \ldots \ldots \ldots \ldots \ldots \ldots \ldots \ldots \ldots$

Tabela 21. Resumo dos principais resultados dos diferentes ex perimentos 


\section{LISTA DE FIGURAS}

página

Figura 1. Arranjo experimental utilizado para infiltração de soluções no solo

Figura 2. Pontos experimentais e curvas de passagem teöricas para $\mathrm{Cl}^{-}$e uréia na coluna 1. Solo: Podzólico Ver melho-Amarelo $\ldots \ldots \ldots \ldots \ldots \ldots \ldots \ldots \ldots \ldots \ldots \ldots$

Figura 3. Pontos experimentais e curvas de passagem teóricas para $\mathrm{Cl}^{-}$e uré1a na coluna 2 . Solo: Podzólico Ver melho-Amarelo $\ldots \ldots \ldots \ldots \ldots \ldots \ldots \ldots \ldots \ldots \ldots \ldots$

Figura 4. Pontos experimentais e curvas de passagem teóricas para alimentação contínua e pulso de uréia na colü na 3. Solo: Podzólico Vermelho-Amarelo .........

Figura 5. Distribuições experimental e teórica da uréia ao longo da coluna 3. Solo: Podzólico Vermelho-Amare

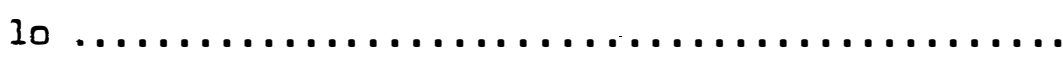

Figura 6. Pontos experimentais e curvas de passagem teóricas para alimentação contínua e pulso de uréia na colü

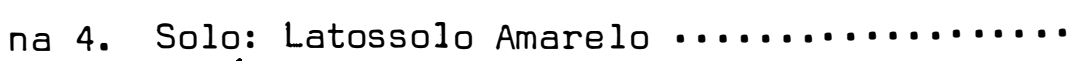


Figura 7. Distribuições experimental e teórica de uréla ao longo da coluna 4. Solo: Latossol Amarelo........

Figura 8. Pontos experimentais e curvas de passagem teóricas para pulso de uréia na coluna 5. Solo: Várzea....

Figura 9. Pontos experimentais e curvas de passagem teóricas para o $2^{8}$ pulso de uréia na coluna 6. Solo: Várzea

Figura 10. Pontos experimentais e curva de passagem teórica para alimentação contínua de uréia na coluna 7 . Solo: Várzea $\ldots \ldots \ldots \ldots \ldots \ldots \ldots \ldots \ldots \ldots \ldots \ldots \ldots$

Figura 11. Distribuições experimental e teórica de uréia ao longo da coluna 7. Solo: Várzea

Figura 12. Distribuição de $\mathrm{NH}_{4}^{+}$e $\mathrm{NH}_{4}^{+}-{ }^{15} \mathrm{~N}$ em função da profun didade para a coluna 7 . Solo: Várzea .......... 
RESUMO

Foi estudado, em laboratório, o deslocamento miscível de uréia em condições de saturação em ägua, em três solos da região Amazônica. Foram utilizadas amostras coletadas da camada 0-30 cm de solos Podzólico Vermelho-Amarelo, Latossolo Amarelo e um solo de várzea às margens do rio Solimões. As amostras foram acondicionadas em cilindros de plástî co acrílico de $5,85 \mathrm{~cm}$ de diámetro interno e $30 \mathrm{~cm}$ de altura, aos quais foi aplicado uréia. Em alguns casos foi utilizada uréia marcada com o isótopo ${ }^{15} \mathrm{~N}$.

Um modelo matemático, desenvolvido a partir da equação diferencial que descreve o deslocamento miscível, ajustou-se perfeitamente aos dados experimentais obtidos para os solos Podzólico e Latossolo, porém falhou em descrever o fenômeno para o solo de várzea. A principal ra zão para esta falha encontra-se na variação da atividade da urease com o tempo neste último solo.

As velocidades do fluxo são importantes para a interpretação correta dos fatores de transformação de uréia. 


\section{xiii}

Nos casos em que foi utilizada uréia marcada, sua recuperação ao final dos experimentos variou de 85 a 107\%. Para os solos Podzó lico e Latossolo a maior parte $(81-87 \%)$ foi recuperada no efluente da coluna, na forma de uréia. Para o solo de várzea a maior parte (60-78\%) foi recuperada no solo, na forma de $\mathrm{NH}_{4}^{+}$trocável. 


\section{SUMMARY}

Samples from the $0-30 \mathrm{~cm}$ layer of three Amazonian soils were used to study miscible displacement of urea, under water saturated conditions, in the laboratory. The soils were: one Red-Yellow Podzol, one Yellow Latosol and one "varzea" soil.

The samples were packed into plexiglass cilinders $5,65 \mathrm{~cm}$ in internal diameter and $30 \mathrm{~cm}$ long, to which urea solution was applied at a constant rate. In some of the columns ${ }^{15} \mathrm{~N}$ labelled urea was used.

A mathematical model, based on the miscible displacement differential equation, fitted perfectly the experimental data for the Podzolic and Latosol soils, but failed for the "varzea" soil. Main reason for this failure is the temporal variation of urease activity in this soil.

Mean flow velocities were found to be important in interpreting correctly urea transformation rates.

Labelled urea recovery ranged from 85 to $107 \%$. For the Podzolic and Latosol, $81-87 \%$ of the total urea applied was found in the 
column effluent, in urea form. For the "varzea" soil 60 to $78 \%$ of the urea applied was found in the soil, in exchangeable $\mathrm{NH}_{4}^{+}$form. 


\section{INTRODUÇAO}

Apesar de ser há muito tempo reconhecida a importância do nitrogênio para as plantas cultivadas, tal fato mereceu atenção redobrada a partir da crise mundial do petróleo.

Isto se faz sentir de maneira mais aguda em um país com as características como o Brasil, de uma alta dependência externa de petróleo, e em franca expansão demográfica, onde existe a necessidade de se au mentar a produção de alimentos para uma população crescente e para resolver problemas de balanço de pagamentos. Tal objetivo pode ser conseguido através do aumento da produtividade e/ou expansão da fronteira agrícola.

0 aumento de produtividade impliea em aumento do uso de fertilizantes nitrogenados, que além do alto custo tem,pelo menos em poten cial, a possibilidade de causar problemas de poluição em águas subterrâneas e superficiais. A expansão da fronteira agrícola exige um esforço no sentido de se conhecer as características e problemas dos solos a serem $\underline{U}$ tilizados.

Na maioria das vezes, tanto na prática como em pesquisa, a 
preocupação de agricultores e cientistas se focaliza na camada superior do solo,onde a aplicação de fertilizantes, herbicidas, água, etc., é medi da pelo comportamento das plantas acima do solo. Pouca atenção tem sido dada aos processos que ocorrem no próprio solo. Por exemplo, pouco se co nhece, em nossas condições, sobre as características de transporte de com postos nitrogenados através de perfis de solo.

Tendo em vista o exposto acima,este trabalho tem por objetivo estudar as características de transporte e transformação da uréia em alguns solos da região Amazônica, procurando-se estimar parâmetros tais como velocidade, dispersão, retenção e transformação. Para tanto foi utí lizada a técnica de deslocamento miscível da uréia, em solo saturado e em condições de laboratório. 


\section{REVISAOO DA LITERATURA}

Chama-se de deslocamento miscível ao fenómeno que ocorre quando um fluido se mistura com, e desloca outro fluido, por exemplo, o movimento de água contendo fertilizantes ou pesticidas dissolvidos, para dentro e através de um solo. O estudo experimental deste fenômeno pode levar a informações importantes sobre a velocidade de fluxo de fluidos, configuração de poros etc., em solos.

Os resultados de experimentos de deslocamento miscível são geralmente interpretados através da análise das mudanças de concentração do soluto no efluente de uma coluna de solo ou material poroso, colocadas numa forma padrão chamada, na literatura internacional "breakthrough curves", e que neste trabalho chama-se de curvas de passagem. Una curva de passagem é um gráfico da concentração relativa do efluente (C/Co) contra o tempo ou volume de poros $\left(\frac{q t}{V_{0}}\right)$ do efluente coletado. Tal definição tornar-se-à mais clara adiante.

Existem na literatura vários modelos matemáticos que tentam descrever curvas de passagem obtidas experimentalmente. Passamos ago 
ra a discutir alguns deles.

Considere-se uma solução de um soluto qualquer dentro de um meio poroso qualquer, e que este soluto não tenha interação alguma com o meio poroso. Sua movimentação se dará por difusão e por fluxo de massa.

A difusão de um soluto pode ser descrita pela lei de Fick, que no caso de movimento unidirecional e umidade constante pode ser escri ta:

$$
q_{D}=-D \theta \frac{\partial c}{\partial x}
$$

onde

$$
\begin{aligned}
&{ }_{D}^{q_{D}=} \text { densidade de fluxo do soluto por difusão } \\
&\left(\mathrm{g} \text { de soluto } / \mathrm{cm}^{2} \text { do meio poroso } \mathrm{s}\right) . \\
& C= \text { concentração do soluto na solução }\left(\mathrm{g} / \mathrm{cm}^{3}\right) \\
& D= \text { coeficiente de difusão do soluto no meio } \\
& \text { poroso }\left(\mathrm{cm}^{2} \text { do meio poroso/s }\right) . \\
& \theta= \text { umidade do meio poroso }\left(\mathrm{cm}^{3}\right. \text { de solução/ } \\
&\text { cm } \left.{ }^{3} \text { do meio poroso }\right) . \\
& x= \text { coordenada vertical de posição }(\mathrm{cm}) \\
& 0 \text { fluxo de massa do soluto é dado por: }
\end{aligned}
$$$$
q_{m}=q \cdot c
$$ 
onde

$$
\begin{aligned}
q_{m}= & \text { fluxo de massa do soluto ( } g \text { do soluto } / \mathrm{cm}^{2} \text { do meio } \\
& \text { poroso.s). } \\
q:= & \text { fluxo de massa da solução }\left(\mathrm{cm}^{3} \text { de solução } / \mathrm{cm}^{2}\right. \text { do } \\
& \text { meio poroso.s }) . \\
C= & \text { concentração do soluto }\left(\mathrm{g} / \mathrm{cm}^{3}\right. \text { solução). }
\end{aligned}
$$

E a densidade de fluxo total de soluto será dada pela soma das densidades de fluxos por fluxo de massa ou seja:

$$
q_{T}=q_{m}+q_{D}
$$

ou ainda

$$
q_{T}=q \cdot C-D \Theta \frac{\partial C}{\partial x}
$$

Daqui por diante, por simplicidade, designar-se-á as densi dades de fluxo por fluxo apenas.

Tomando-se a equação da continuidade para umidade constante, e para uma dimensão apenas:

$$
\Theta \frac{\partial C}{\partial t}=\frac{\partial q T}{\partial x}-
$$

e substituindo-se (4) em (5) tem-se:

$$
\theta \frac{\partial C}{\partial t}=-\frac{\partial}{\partial x}\left(q C-D \theta \frac{\partial C}{\partial x}\right]
$$


e considerando-se também q e $D$ constantes

$$
\Theta \frac{\partial C}{\partial t}=D \theta \frac{\partial^{2} C}{\partial x^{2}}-q-\frac{\partial C}{\partial x}
$$

ou ainda

$$
\frac{\partial C}{\partial t}=D \frac{\partial^{2} C}{\partial x^{2}}-\frac{q}{\theta} \frac{\partial C}{\partial x}
$$

0 termo q/O da equação (8) corresponde à velocidade média da solução nos poros, e na direção do movimento (NIELSEN e BIGGAR 196்2 a; KIRKHAM e POWERS, 1972 p. 400; NIELSEN et alii 1972, p. 37). No caso de soluto não reativo a velocidade do soluto é a própria velocidade da solução.

A equação (8) fica portanto:

$$
\frac{\partial C}{\partial t}=0 \frac{\partial^{2} C}{\partial x^{2}}-v \frac{\partial C}{\partial x}
$$

Nesta última equação, o $2^{2}$ termo à direita corresponde ao fluxo de massa e indica a posição da frente de solução deslocada. $0 \quad 1^{8}$ termo à direita corresponde à difusão, mas na realidade ele indica a dispersão do soluto ou espessura de transição (BIGGAR e NIELSEN, 1976b). De ve aqui ser chamada a atenção para uma certa confusão existente na litera tura em relação ao parāmetro D. Apesar de ter sido chamado de coeficiente de difusão do soluto no meio poroso, durante o desenvolvimento da equa ção (9), ele é, na realidade, o resultado da interação de dois mecanismos: 
difusão propriamente dita e convecção (BOAST 1973). No caso de água fluindo através de um solo, ela não se move com a mesma velocidade, mesmo através de um único poro, onde a velocidade é menor junto à parede que no centro (TAYLOR, 1953). Mais ainda, o fluxo é maior em poros maiores e ela não se move em linha reta (BOAST, 1973). Estes três efeitos agindo conjuntamente causam uma variação da distribuição de velocidades da solução nos poros, resultando num fenōmeno frequentemente chamado de dispersão hidrodinâmica (DAY e FORSYTHE, 1957). A diferença entre dispersão hí drodinâmica e difusão molecular é que a primeira somente ocorre quando existe movimento de água no solo. A dispersão hidrodinámica obedece uma lei de proporcionalidade que tem a mesma forma que a lei de Fick (equação 1) para difusão molecular, de maneira que o parâmetro $D$ da equação (9) se ria, segundo BOAST (1973):

$$
D=K+D_{m}
$$

sendo

$$
\begin{aligned}
D & =\text { dispersão de um soluto no solo } \\
K & =\text { coeficiente de dispersão longitudinal } \\
D_{m} & =\text { coeficiente de difusão molecular do soluto. }
\end{aligned}
$$

Já BIGGAR e NIELSEN (1964) preferem chamar tal paràmetro de coeficiente de difusão aparente do soluto. Neste trabalho chamar-se-á o parâmetro 0 de dispersão simplesmente.

Vários autores propuseram relações matemáticas procurando 
correlacionar a dispersão do soluto no solo $\mathrm{D}\left(\mathrm{cm}^{2} / \mathrm{s}\right)$ com a difusão molecular do mesmo na água e com a velocidade da água nos poros. Assim FRIS SEL e PCELSTRA (1967) propuseram a equação:

$$
\begin{aligned}
& \mathrm{D}=\mathrm{D}_{\mathrm{H}_{2} \mathrm{O}} \ominus \gamma+\lambda d \mathrm{~V}_{\mathrm{H}_{2} \mathrm{O}} \ldots \ldots \ldots \ldots \ldots \ldots \ldots \text { (1I) } \\
\mathrm{D}_{\mathrm{H}_{2} \mathrm{O}}= & \text { coeficiente de difusão do soluto em àgua }\left(\mathrm{cm}^{2} / \mathrm{s}\right) \\
\gamma \quad= & \text { fator de tortuosidade (adimensional) } \\
\lambda \quad \text { fator de empacotamento ou geometria das partículas } & \text { (adimensional) }
\end{aligned}
$$$$
V_{\mathrm{H}_{2} \mathrm{O}}=\text { velocidade da água nos poros do solo }(\mathrm{cm} / \mathrm{s})
$$$$
\text { d } \quad=\text { diâmetro das partículas }(\mathrm{cm})
$$$$
\Theta, D \quad j a ́ \text { definidos }
$$

KIRDA et alii (1973) e BIGGAR e NIELSEN (1976a) sugerem a seguinte relação:

$$
D=D_{H_{2}} \mathrm{O} \gamma+a v^{n}
$$

ou

$$
D=D e f+a v^{n}
$$

onde

Def = coeficiente de difusão molecular do soluto no so 
$10\left(\mathrm{~cm}^{2} / \mathrm{s}\right)$

a e $\underline{n}=$ parâmetros de correlação sendo que NIELSEN et alii (1972) concluiram que para velocidades menores que $0.2 \mathrm{~cm} /$ dia a dispersão torna-se prati camente igual ao coeficiente de difusão molecular efetivo.

Já REICHARDT (1975) preferiu utilizar a seguinte relação:

$$
\text { Def }=D_{\mathrm{H}_{2} \mathrm{O}} \cdot \Theta \cdot \gamma^{2} \cdot \delta \cdot K
$$

onde

$$
\begin{aligned}
& \delta=\text { viscosidade da solução (adimensional) } \\
& K=\text { adsorção do soluto (adimensional) } \\
& \text { Def, } D_{\mathrm{H}_{2} \mathrm{O}} \Theta \text { e } \gamma \text { já definidos. }
\end{aligned}
$$

Fica portanto patente a relação existente entre a dispersão e propriedades do solo e da solução do solo, estando o seu valor condicionado a fatores tais como umidade do solo (PORTER et alii, 1960; NIEL SEN e BIGGAR, 1962a), tipo de soluto (COREY et alii, 1963), textura do so lo (CASSEL et alii, 1974; CASSEL et alii, 1975), velocidade média da água nos poros (NIELSEN e BIGGAR, 1962a, 1963; FRISSEL e POELSTRA 1967; NIELSEN et alii 1972; HASHIMOTO et alii, 1964; BIGGAR e NIELSEN 1976a; SELIM et alii 1976a; MISRA e MISHRA, 1977; SIDLE et alii, 1977). 
Conforme as condições experimentais estabelecem-se condições de contorno particulares para se obter a solução analítica da equação (9). Em casos onde não é possível uma solução analítica ela é resolvida por cálculo numérico.

2.1. Deslocamento miscĩvel com solutos inertes e alimentação contínua

Seja o caso de uma coluna de solo com fluxo de água em equilíbrio dinâmico. A partir de um certo instante inicia-se a infiltração de uma solução do soluto em estudo, mantendo-a ininterruptamente. As condições inicial e de contorno são então as seguintes:



onde

$$
\begin{aligned}
\text { Co = } & \text { concentração inicial do soluto na solução desloca- } \\
& \text { dora }\left(\mathrm{g} / \mathrm{cm}^{3}\right) \\
x= & \text { distância }(\mathrm{cm}) \text { da coluna ou perfil de solo } \\
t= & \text { tempo de infiltração da solução (s) } \\
c= & \text { concentração da solução no efluente para uma dis- } \\
& \text { tância } x \text { e tempo } t .
\end{aligned}
$$

Para um soluto que não sofra interações de espécie alguma com o solo, a solução analítica da equação (9) sujeita às condições de contorno acima, é dada por KIRKHAM e POWERS (1972, p. 417) e também por 
NIELSEN E BIGGAR (1962b), como sendo:

$$
\frac{c}{C o}=\frac{1}{2}\left(\operatorname{erfc}\left(\frac{x-v t}{\sqrt{4 D t}}\right)+e^{\frac{v x}{D}} \operatorname{erfc}\left(\frac{x+v t}{\sqrt{4 D t}}\right)\right]
$$

onde erfc è a função de erro complementar.

O primeiro membro da equação (18) representa a concentração relativa de soluto no efluente da coluna ou perfil de solo para uma distância $x$, tempo $t$, velocidade média $v$ e dispersão $D$. Percebe-se que, mantidos constantes $x, v$ e obtém-se uma relação entre concentração rela tiva e tempo de infiltração, que colocada em forma gráfica resulta na cur va de passagem.

A equação (18) também pode ser representada em função do volume de poros infiltrado. O volume de poros, ou simplesmente número de poros é definido como o volume de solução deslocadora passada pelo solo (V), em relação ao volume de poros ocupado pela água na coluna ou perfil de solo $\left(V_{0}\right)$ ou seja

$$
P=\frac{V}{V_{0}}
$$

Pela definição percebe-se facilmente que para solos satura dos $v_{0}$ torna-se izual ao próprio volume de poros do solo. Pode também ser demonstrado que:

$$
P=-\frac{v t}{L}
$$


onde

$$
L=\text { comprimento }(\mathrm{cm}) \text { da coluna ou perfil de solo. }
$$

Substituindo a equação (18b) na equação (18) resulta

$$
\frac{C}{C o}=\frac{1}{2}\left[\operatorname{erfc}\left(\frac{1-P}{\sqrt{\frac{4 D P}{V L}}}\right)+e^{-\frac{V L}{D}} \operatorname{erfc}\left(\frac{1+P}{\sqrt{\frac{4 D P}{V L}}}\right)\right]
$$

que resulta em curvas de passagem em função do número de poros deslocados.

$$
\text { BERAN (1955), citado por Biggar e Nielsen (1967) e também }
$$
DANCKWERTS (1953), citado por Nielsen e Biggar (1962b), propuseram uma equação diferencial mais simples

$$
\frac{\partial C}{\partial t}=D \frac{\partial^{2} C}{\partial x^{2}}
$$

onde $D$ é chamado de "fator de dispersão" resultando somente do mecanismo de dispersão hidrodināmica, não envolvendo portanto o mecanismo de difusão. O modelo foi desenvolvido estatisticamente e resultou numa solução do tipo

$$
\frac{c}{C o}=\frac{1}{2}\left(\operatorname{erfc}\left(\frac{x-v t}{\sqrt{4 D t}}\right)\right)
$$

ou em função do número de poros

$$
\frac{C}{C o}=\frac{1}{2}\left(\operatorname{erfc}\left(\frac{I-P}{\sqrt{\frac{4 D P}{V L}}}\right)\right)
$$


Lma particularidade destas duas ültimas equações é que, quando for deslocado exatamente um volume de poros, a concentração relativa no efluente terá que ser igual a 0,5 , já que por definição erfc $(0)=$ 1. Este modelo se ajusta razoavelmente bem para materiais com poros contínuos e altas velocidades de infiltração (KIRKHAM e POWERS 1972, p.419), porém falha ao tentar descrever curvas de passagem em materiais insaturados (BIGGAR e NIELSEN 1962; NIELSEN e BIGGAR, 1961) e outros resultados de experimentos tanto de laboratório como de campo.

Já nas equações (18) e (19), para que C/Co seja igual a 0,5 ao se deslocar um volume de poros, é necessário haver um balanceamento perfeito entre a exponencial e a função de erro complementar no $2^{8}$ ter mo do $2^{8}$ membro das equações, ou seja, que ambas as funções se cancelem. Isto vai depender da geometria de poros e da velocidade média do fluxo.

NIELSEN e BIGGAR 1962a) e BIGGAR e NIELSEN (1964) utilizan do as equações (18) e (19) conseguiram excelentes resultados para descrever as curvas de passagem do íon $\mathrm{Cl}^{-}$tanto em solos como em esferas de ví dro. Estas duas equações têm sido utilizadas para descrever a movimentação de solutos inertes, tais como $\mathrm{Cl}^{-}$, água tritiada, durante o deslocamento miscível em solos nas mais variadas condições, visando principalmen te determinar as características de velocidade de fluxo e sua dispersão (NIELSEN e BIGGAR, 1963; BIGGAR e NIELSEN, 1964; COREY et alii 1967; CASSEL, 1971; CASSEL et alii 1974, 1979; CASTRO e ROLSTON, 1977; NASCIMENTO $\left.F^{8}, 1978\right)$. 
2.2. Deslocamento miscivel de um pulso de soluto inerte

Neste caso um pulso de solução deslocadora contendo o solü to é deixado infiltrar por um tempo $t_{1}$, após o qual retorna-se à infiltra ção com água. As condições de contorno são então as seguintes:

$$
\begin{array}{lll}
c=0 & x>0 & t=0 \ldots \ldots \\
c=C_{0} & x=0 & 0<t<t_{1} \\
c=0 & x=0 & t>t_{1} \ldots
\end{array}
$$

sendo $t_{1}=$ tempo de infiltração da solução deslocadora contendo o soluto (s) e as demais variáveis já definidas anteriormente.

A solução da equação (9), sujeita às condições de contorno acima é dada por BIGGAR e NIELSEN (1976a)

$$
\begin{gathered}
\frac{C}{C 0}=\frac{1}{2}\left|\operatorname{erfc}\left(\frac{x-v t}{\sqrt{4 D t}}\right)+e^{\frac{v x}{D}} \operatorname{erfc}\left(\frac{x+v t}{\sqrt{4 D t}}\right)\right| \\
-\frac{1}{2}\left|\operatorname{erfc}\left(\frac{x-v\left(t-t_{1}\right)}{\sqrt{4 D\left(t-t_{1}\right)}}\right)+e^{\frac{v x}{D}} \operatorname{erfc}\left(\frac{x+v\left(t-t_{1}\right)}{\sqrt{4 D\left(t-t_{1}\right)}}\right)\right|
\end{gathered}
$$

NASCIMENTO $F^{8}$ (1978) sugere que seja utilizada a relação

$$
P=v\left(\frac{t-0,5 t_{1}}{L}\right)
$$

para transformar a equação (26) para uma função do volume de poros deslocados. Este mesmo autor utilizou a equação (26) para descrever o deslo- 
camento miscível do íon cloreto em condições de campo obtendo uma ótima concordância entre os dados experimentais obtidos e os calculados pela equação. A mesma equação também foi utilizada por CASTRO e ROLSTON (1977) com o intuito de se determinar o valor da dispersão de um solo para uso posterior na predição do movimento e hidrólise de glicerofosfato no mesmo solo.

Outros autores se utilizaram de outros modelos. Assim, COREY et alii (1963) se utilizaram da solução da equação (19a) proposta por KIRKHAM e POWERS (1972, P. 403), estudando o movimento conjunto. de água tritiada e $\mathrm{Cl}^{-}$em colunas de areia e, determinando o valor da disper são para estes íns em diversas condições de umidade e velocidade de infiltração, observaram também um certo atraso da curva do trítio em relação à do cloreto.

CASSEL et alii (1974) se utilizaram do modelo proposto por BRENNER (1962), modificando as condições de contorno para resolver a equa ção (9) para um pulso de soluto, estudando a movimentação de $\mathrm{CL}^{-}$e $\mathrm{NO}_{3}^{-}$em solos com estruturas deformada e não deformada. Constataram que o fato de se perturbar um solo leva a diferenças significativas nas suas caracte rísticas de meio de transporte devendo-se tomar muito cuidado ao se tentar extrapolar resultados de laboratório para condições de campo.

\subsection{Deslocamento miscivel com o soluto sujeito a reações reversiveis}

São consideradas reações reversíveis os processos de troca a que estão sujeitos certos íons no solo. Neste caso, a equação (9) deve ser modificada para incluir um novo termo: 


$$
\frac{\rho}{\theta} \frac{\partial S}{\partial t}+\frac{\partial C}{\partial t}=D \frac{\partial^{2} C}{\partial x^{2}}-v \frac{\partial C}{\partial x}
$$

onde

$$
\begin{aligned}
\rho= & \text { densidade do solo (g de solo/ } \mathrm{cm}^{3} \text { de solo) } \\
S= & \text { concentração na fase adsorvida ou de troca (g so- } \\
& \text { luto } / \mathrm{cm}^{3} \text { solução). }
\end{aligned}
$$

Em equilíbrio, a adsorção pode ser expressa, em alguns casos, por uma equação linear da forma

$$
S=K C+a
$$

Desta maneira

$$
\frac{\partial S}{\partial t}=k \frac{\partial C}{\partial t}
$$

que substituida na equação (28) resulta em:

$\left(1+\frac{\rho K}{\theta}\right) \frac{\partial C}{\partial t}=D-\frac{\partial^{2} C}{\partial x^{2}}-v \frac{\partial C}{\partial x}$

ou fazendo

$$
R=1+\frac{\rho K}{\theta}
$$

fica

$$
R \frac{\partial C}{\partial t}=0 \frac{\partial^{2} C}{\partial x^{2}}-v \frac{\partial C}{\partial x}
$$


ou

$$
\frac{\partial C}{\partial t}=\frac{D}{R} \frac{\partial^{2} C}{\partial x^{2}}-\frac{v}{R} \frac{\partial C}{\partial x} \ldots \ldots \ldots \ldots \ldots \ldots
$$

As soluções analíticas da equação (34) são idênticas às já apresentadas anteriormente diferindo apenas nos termos em $D$ e $v$ que passam a ser divididos pelo fator R. Por exemplo, para um pulso de solução deslocadora, a solução analítica da equação (34) é:

$$
\begin{aligned}
& \frac{C}{C O}=\frac{1}{2}\left[\operatorname{erfc}\left(\frac{x-\frac{v}{R} t}{\left.\sqrt{4 \frac{D}{R} t}\right)}+e^{\frac{v x}{D}}-\operatorname{erfc}\left(\frac{x+\frac{v}{R} t}{\sqrt{4 \frac{D}{R} t}}\right)\right]\right. \\
& -\frac{1}{2}\left[\operatorname{erfc}\left(\frac{x-\frac{v}{R}\left(t-t_{1}\right)}{\sqrt{4 \frac{D}{R}\left(t-t_{1}\right)}}\right)+e^{\frac{v x}{D}} \operatorname{erfc}\left(\frac{x+\frac{v}{R}\left(t-t_{1}\right)}{\sqrt{4 \frac{D}{R}\left(t-t_{1}\right)}}\right) \ldots \ldots\right.
\end{aligned}
$$

semelhante à equação (26).

Em muitos casos o fenōmeno de adsorção não pode ser descrị to por uma equação linear. Assim, SELIM et alii (1976b) e SELIM et alii (1977) estudando o transporte de potássio em solos, SIDLE et alii (1977) estudando o transporte de metais pesados em solos, e DAVIDSON et alii (1976) estudando o comportamento de pesticidas em solos expressaram a adsorção pela isoterma de Freundlich, que tem a forma

$$
S=K c^{N}
$$


sendo $R$ dado então por:

$$
R=1+\frac{\rho^{K}}{\theta} N c^{N-1}
$$

DAVIDSON et alii (1972) e VAN GENUTCHEN et alii (1974) estudando o movimento de pesticidas em solos utilizaram equações de cinética de adsorção-dessorção, da forma

$$
D \stackrel{K_{A}}{\underset{K_{D}}{\rightleftharpoons}} s
$$

sendo a taxa de transferéncia para a fase adsortiva dada por:

$$
\frac{\partial S}{\partial t}=K_{A} \cdot \frac{\rho}{\theta} \cdot C-K_{D} S
$$

ou

$$
\frac{\partial S}{\partial t}=K_{D}\left(K^{\prime} C-S\right)
$$

sendo $K_{A}$ e $K_{D}$ os coeficientes de adsorção e dessorção respectivamente, e $K^{\prime}=K_{A} \Theta / K_{D} \rho$.

SELIM et alii (1976c) propuseram um modelo em que utilizaram dois sítios de adsorção-dessorção no solo; o primeiro, chamado tipo I, caracterizado por equilíbrio instantâneo, e o segundo, chamado de tipo II, caracterizado por equilíbrio dependente de tempo. As equações utilizadas foram: 


$$
\frac{\partial S_{I}}{\partial t}=\frac{\theta}{\rho} K_{1} C^{N}-K_{2} S_{I}
$$

para os sítios do tipo I e

$$
-\frac{\partial S_{I I}}{\partial t}=\frac{\theta}{\rho} K_{3} C^{N}-K_{4} S_{I I}
$$

para os sítios do tipo II, sendo

$$
\begin{aligned}
K_{1} \text { e } K_{3}= & \text { coeficientes de adsorção }\left(s^{-1}\right) \text { para os sítios I } \\
& \text { e II respectivamente }
\end{aligned}
$$

$$
\begin{aligned}
\mathrm{K}_{2} \text { e } \mathrm{K}_{4}= & \text { coeficientes de dessorção para os tipos I e } \\
& \text { respectivamente }
\end{aligned}
$$
II

Este modelo foi utilizado com sucesso por CAMARGO et alii (1979) e por HOFFMAN e ROLSTON (1980) para descrever o transporte de compostos fosforados em solos.

VAN GENUTCHEN E WIERENGA (1976) utilizaram o modelo propos to por COATS e SMITH (1964), que considera regiões onde a água é imóvel expandindo-o para inclusão da adsorção linear, utilizando as seguintes equações diferenciais:

$$
\begin{aligned}
& \frac{\partial(\Theta m C m)}{\partial t}+\frac{\partial(\Theta \dot{m} \lim )}{\partial t}+\frac{\partial(F \rho S m)}{\partial t}+\frac{\partial|(1-F) \operatorname{Sim}|}{\partial t}= \\
= & \frac{\partial}{\partial z}\left(\Theta_{m} D \frac{\partial C m}{\partial Z}\right)-\frac{\partial(q C m)}{\partial Z} \ldots \ldots \ldots \ldots \ldots \ldots
\end{aligned}
$$




$$
\theta i m \frac{\partial \operatorname{Cim}}{\partial t}+(1-F) \frac{\partial \operatorname{Sim}}{\partial t}-\alpha(\operatorname{Cm}-\operatorname{Cim})
$$

sendo a equação (44) chamada de equação de transferência entre as fases mó vel (m) e imóvel (im) da água, S a quantidade de soluto adsorvido e $F$ é a fração de sítios adsortivos na fase móvel. Este modelo foi utilizado pelos mesmos autores (VAN GENUTCHEN e WIERENGA, 1977) no estudo da movimentação de água tritiada em condições de saturação, com excelentes resultados.

2.4. Deslocamento miscivel com soluto sujeito a reações irreversĩveis

Muitos compostos são passíveis de sofrer transformações ir reversíveis de natureza biológica ou química, como por exemplo os compostos de nitrogênio, enxofre etc.

Neste caso a equação diferencial que descreve o movimento de solutos fica:

$$
\frac{\partial S}{\partial t}+\frac{\partial C}{\partial t}=D \frac{\partial^{2} C}{\partial x^{2}}-v \frac{\partial C}{\partial x} \pm \phi
$$

onde o termo $\phi$ representa uma fonte ou sumidouro irreversível, e os demais termos já foram definidos anteriormente.

Para o caso de transformações biológicas, pode-se descrevê las por termos de ordem zero (transformação independente da concentração) ou por reações de primeira ordem, seguindo a cinética de Michaelis Menten, 
onde a velocidade da reação é dependente da concentração. A reação de or dem zero ocorre somente com altas concentrações do substrato quando compa rado com o Km da reação. Para concentrações menores do substrato, ou em condições de baixo suprimento de energia para os microrganismos a reação é de primeira ordem (STARR et alii 1974).

Para reações de la. ordem a equação (45) fica:

$$
\frac{\partial S}{\partial t}+\frac{\partial C}{\partial t}=D \frac{\partial^{2} C}{\partial x^{2}}-v \frac{\partial C}{\partial x}-k C
$$

onde $K=$ fator de transformação $\left(s^{-1}\right)$

ou ainda

$$
\frac{\partial C}{\partial t}=\frac{D}{R} \frac{\partial^{2} C}{\partial x^{2}}-\frac{v}{R}-\frac{\partial C}{\partial x}-\frac{K}{R} C
$$

sendo R dado pela equação (32).

Para solutos que não sofrem adsorção:

$$
\frac{\partial C}{\partial t}=D \frac{\partial^{2} C}{\partial x^{2}}-v \frac{\partial C}{\partial x}-k
$$

e a solução analítica para condições de alimentação contínua está sujeita às seguintes condições inicial e de contorno (D.E. ROLSTON, julho de 1980 comunicação pessoall 


$$
\begin{array}{lll}
C=0 & t=0 & x \geqslant 0 \\
C=\text { Co } & t>0 & x=0 \\
C=0 & t>0 & x \rightarrow \infty
\end{array}
$$

é é dada por:

$$
\begin{aligned}
& \frac{c}{C o}=\frac{1}{2}\left\{\exp \left|\frac{x}{2 D}\left(v-\sqrt{v^{2}+4 D K}\right)\right| \operatorname{erfc}\left(\frac{x-t \sqrt{v^{2}+4 D K}}{\sqrt{4 D K}}\right)-\right. \\
& +\exp \left|\frac{x}{2 D}\left(v+\sqrt{v^{2}+4 D K}\right)\right| \operatorname{erfc}\left(\frac{x+t \sqrt{v^{2}+4 D K}}{\sqrt{4 D K}}\right) \ldots \ldots \ldots \ldots
\end{aligned}
$$

e para condições de infiltração de um pulso de soluto, as condições inicial e de contorno são:

$$
\begin{array}{lll}
c=0 & t=0 & x \geqslant 0 \\
c=c o & 0<t<t_{1} & x=0 \\
c=0 & t \geqslant t_{1} & x=0
\end{array}
$$

e a solução analítica é dada por CHO (1971)

$$
\frac{C}{C o}=\text { equação (52) para } 0<t<t_{1}
$$

e

$$
\begin{aligned}
& \quad \frac{c}{C o}=\frac{1}{2} \exp \left\{\frac{x}{2 D}\left(v-\sqrt{v^{2}+4 D K}\right) \operatorname{erfc}\left(\frac{x-t \sqrt{v^{2}+4 D K}}{\sqrt{4 D t}}\right)\right. \\
& +\exp \left\{\frac{x}{2 D}\left(v+\sqrt{v^{2}+4 D K}\right)\right\} \operatorname{erfc}\left(\frac{x+t \sqrt{v^{2}+4 D K}}{\sqrt{4 D t}}\right)
\end{aligned}
$$




$$
\begin{aligned}
& -\exp \left\{\frac{x}{2 D}\left(v-\sqrt{v^{2}+4 D K}\right)\right\} \operatorname{erfc}\left(\frac{x-\left(t-t_{1}\right) \sqrt{v^{2}+4 D K}}{\left.\sqrt{4 D\left(t-t_{1}\right.}\right)}\right) \\
& -\exp \left\{\frac{x}{2 D}\left(v+\sqrt{v^{2}+4 D K}\right)\right\} \operatorname{erfc}\left(\frac{x+\left(t-t_{1}\right) \sqrt{v^{2}+4 D K}}{\sqrt{4 D\left(t-t_{1}\right)}}\right) \mid \ldots \ldots(57)
\end{aligned}
$$

sendo a equação (57) válida para $t>t_{1}$.

Percebe-se que, para $K=0$ as equações (52) e (57) tornamse iguais às equações (18) e (26), respectivamente.

0 elemento que mais tem sido estudado no que diz respeito a transporte e transformações é o nitrogênio, devido a característica sequencial de reações a que está sujeito no solo. Por exemplo, a partir de amônio, são possíveis as seguintes reações:

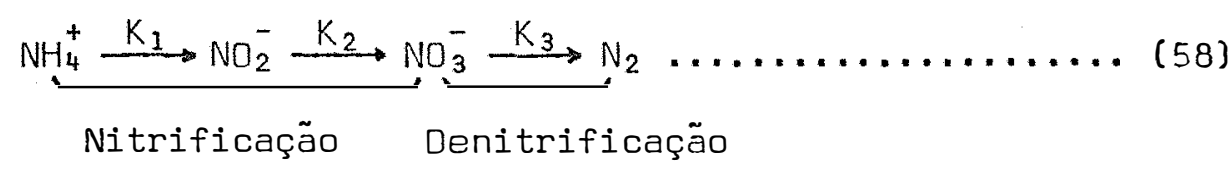

MCLAREN (1970) considera uma reação em cadeia do tipo acima, resolvendo analiticamente o sistema de equações diferenciais dando ên fase aos processos microbiológicos, porém sem considerar o transporte dis persivo.

CHO (1971) utilizou uma série de equações do tipo da equação (48), acopladas de maneira a descrever o transporte de amônio, com ní trificação, em um solo: 


$$
\begin{aligned}
& \frac{\partial C_{1}}{\partial t}=\frac{D}{R} \frac{\partial^{2} C_{1}}{\partial x^{2}}-\frac{v}{R} \frac{\partial C_{1}}{\partial x}-\frac{K_{1}}{R} C_{1} \ldots \ldots \ldots \text { (59) } \\
& \frac{\partial C_{2}}{\partial t}=0 \frac{\partial^{2} C_{2}}{\partial x^{2}}-v \frac{\partial C_{2}}{\partial x}+K_{1} C_{1}-K_{2} C_{2} \ldots \ldots \ldots \text { (60) } \\
& \frac{\partial C_{3}}{\partial t}=D \frac{\partial^{2} C_{2}}{\partial x^{2}}-v \frac{\partial C_{3}}{\partial x}+K_{2} C_{2}-K_{3} C_{3} \ldots \ldots \ldots \text { (61) }
\end{aligned}
$$

onde os subscritos 1,2 e 3 se referem a $\mathrm{NH}_{4}^{+}, \mathrm{NO}_{2}^{-}$e $\mathrm{NO}_{3}^{-}$, respectivamente. Percebe-se que o acoplamento é feito através de termos como por exemplo $K_{2} C_{2}$, que é sumidouro na equação (60) e fonte na equação (61).

STARR et alii (1974) e MISRA et alii (1974a,b) utilizaram o modelo proposto por CHO (1971) para estudar a nitrificação e denitrificação durante o transporte de amônia em colunas de solo não saturado, em equilíbrio dinâmico. Consideraram desprezível a passagem por nitrito, já que sua oxidação é extremamente rápida (MCLAREN 1970), e simplificaram o modelo utilizando equações de "steady-state", determinando então as taxas de transformação de $\mathrm{NH}_{4}^{+}$e $\mathrm{NO}_{3}^{-}$através de ajuste de curvas.

MISRA et alii (1974c) utilizaram-se deste mesmo modelo para estudar a redução do nitrato durante o transporte de um pulso deste mesmo composto através de uma coluna de solo em condições de equilíbrio dinâmico não saturado. Estudaram a influência de parâmetros, tais como concentração de oxigênio e temperatura, na taxa de redução de nitrato. 
guintes equações para descrever as reações sequenciais de transporte de uréia em solos não saturados:

$$
\begin{gathered}
\left(1+R_{1}\right)-\frac{\partial C_{1}}{\partial t}=D \frac{\partial^{2} C_{1}}{\partial x^{2}}-v \frac{\partial C_{1}}{\partial x}-k_{1} C_{1} \ldots \ldots \ldots \ldots \text { (62) } \\
\left(1+R_{2}\right) \frac{\partial C_{2}}{\partial t}=D \frac{\partial^{2} C_{2}}{\partial x^{2}}-v \frac{\partial C_{2}}{\partial x}+K_{1} C_{1}-K_{2} C_{2} \ldots \ldots \ldots \text { (63) } \\
\frac{\partial C_{3}}{\partial t}=D \frac{\partial^{2} C_{3}}{\partial x^{2}}-v \frac{\partial C_{3}}{\partial x}+K_{2} C_{2}-K_{3} C_{3} \ldots \ldots \ldots \ldots(64)
\end{gathered}
$$

onde os subscritos 1,2 e 3 referem-se a uréia, $\mathrm{NH}_{4}^{+}$e $\mathrm{NO}_{3}^{-}$respectivamente, e os termos $\left(1+R_{1}\right)$ e $\left(1+R_{2}\right)$ a adsorção linear de uréia e $\mathrm{NH}_{4}^{+}$. Estes últi mos termos são equivalentes aos parâmetros $\underline{R}$ usados nas equações citadas anteriormente.

As soluções analíticas das equações (58), (59) e (60) são apresentadas por WAGENET et alii (1976). São apontadas falhas na predição da ordem das reações de transformação, e é chamada a atenção para a importáncia de se levar em consideração a população e a atividade microbiana.

Mais recentemente, os mesmos princípios aqui discutidos tem sido utilizados na tentativa de descrever o transporte e transformação de gases no solo (ROLSTON e GLAUZ, 1980; BROWN e ROLSTON, 1980).

0 deslocamento miscível com infiltração em regime transien te não será aqui discutido. Vários modelos neste sentido tem sido propos tos na literatura, conforme pode ser visto em NASCIMENTO FP (1978). 


\section{MATERIAL E METODOS}

\subsection{Solos utilizados}

Foram utilizadas amostras coletadas da camada $0-30 \mathrm{~cm}$ de três solos com características físicas distintas.

O solo designado por A é um Podzólico Vermelho-Amarelo de textura média, e foi coletado às margens da estrada Manaus-Caracaraí (Km60), dentro de uma área desmatada onde se encontra instalado o experimento de Agricultura Ecológica sob responsabilidade do Instituto Nacional de Pesquisas da Amazônia (INPA). O solo B é um Latossolo Amarelo, de textura argilosa, coletado na mesma área que o solo A. O solo C foi coletado a cerca de 15 m da margem esquerda do rio Solimões, num local próximo ao encontro das águas; sendo sujeito a inundações anuais, tem características hidromórficas.

Algumas características físicas (mecânicas) e químicas dos três solos são apresentadas na tabela 1. As análises foram feitas pela Seção de Fertilidade de Solos do Instituto Agronômico de Campinas, de acordo com a metodologia descrita por VAN RAIJ e ZULLO (1977). 







\subsection{Arranjo experimental}

As amostras de solo, depois de secas ao ar e passadas por peneira de $2 \mathrm{~mm}$ de malha, foram "acondicionadas" em cilindros de plástico acrílico de $30 \mathrm{~cm}$ de comprimento e $5,65 \mathrm{~cm}$ de diâmetro interno, de modo mais uniforme possível. Cada coluna, montada conforme o esquema mostrado na figura 1, foi inicialmente saturada, de baixo para cima para evitar bo Thas de ar dentro da coluna, com uma solução de $\mathrm{CaSO}_{4}$ 0,01N. A função do $\mathrm{CaSO}_{4}$ é somente a de manter a argila floculada.

Após a saturação iniciou-se a infiltração de $\mathrm{CaSO}_{4} \quad 0,01 \mathrm{~N}$ através da bureta de Mariotti e torneira 1. Este arranjo experimental ga rante a manutenção de um gradiente hidráulico unitário.

Após o estabelecimento de fluxo constante no efluente da coluna, fechando-se a torneira 1 e abrindo-se a torneira 2, permite-se a infiltração da solução de $\mathrm{CaSO}_{4}$ 0,01N contendo também uma quantidade prédeterminada de uréia, marcada ou não com o isótopo ${ }^{15} \mathrm{~N}$. A partir deste instante o efluente da coluna começou a ser coletado, a tempos constantes, em um coletor automático de frações marca Toyo.

Foram preparadas um total de 7 colunas: 3 com o solo A, 3 com o solo C e uma com o solo B. As características que envolveram cada experimento em particular são mostradas na tabela 2.

As amostras do efluente de cada coluna foram analisadas pa ra determinação da concentração de uréia e $\mathrm{NH}_{4}^{+}$, e $\mathrm{Cl}^{-}$quando para as colü nas 1 e 2. Para análise da uréia foi utilizado o método colorimétrico de 


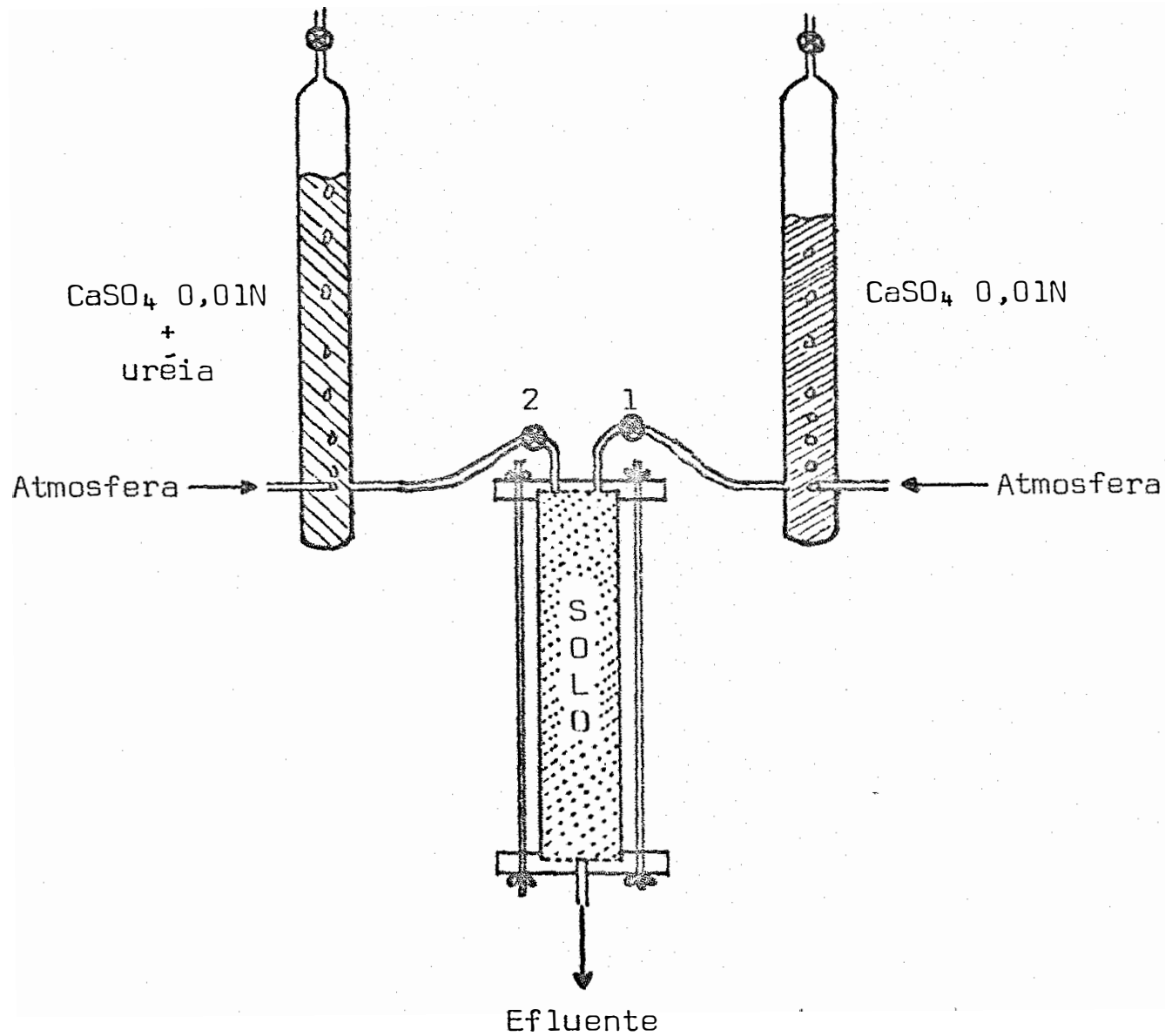

Fig. 1 - Arranjo experimental utilizado para infiltração de soluções no solo. 


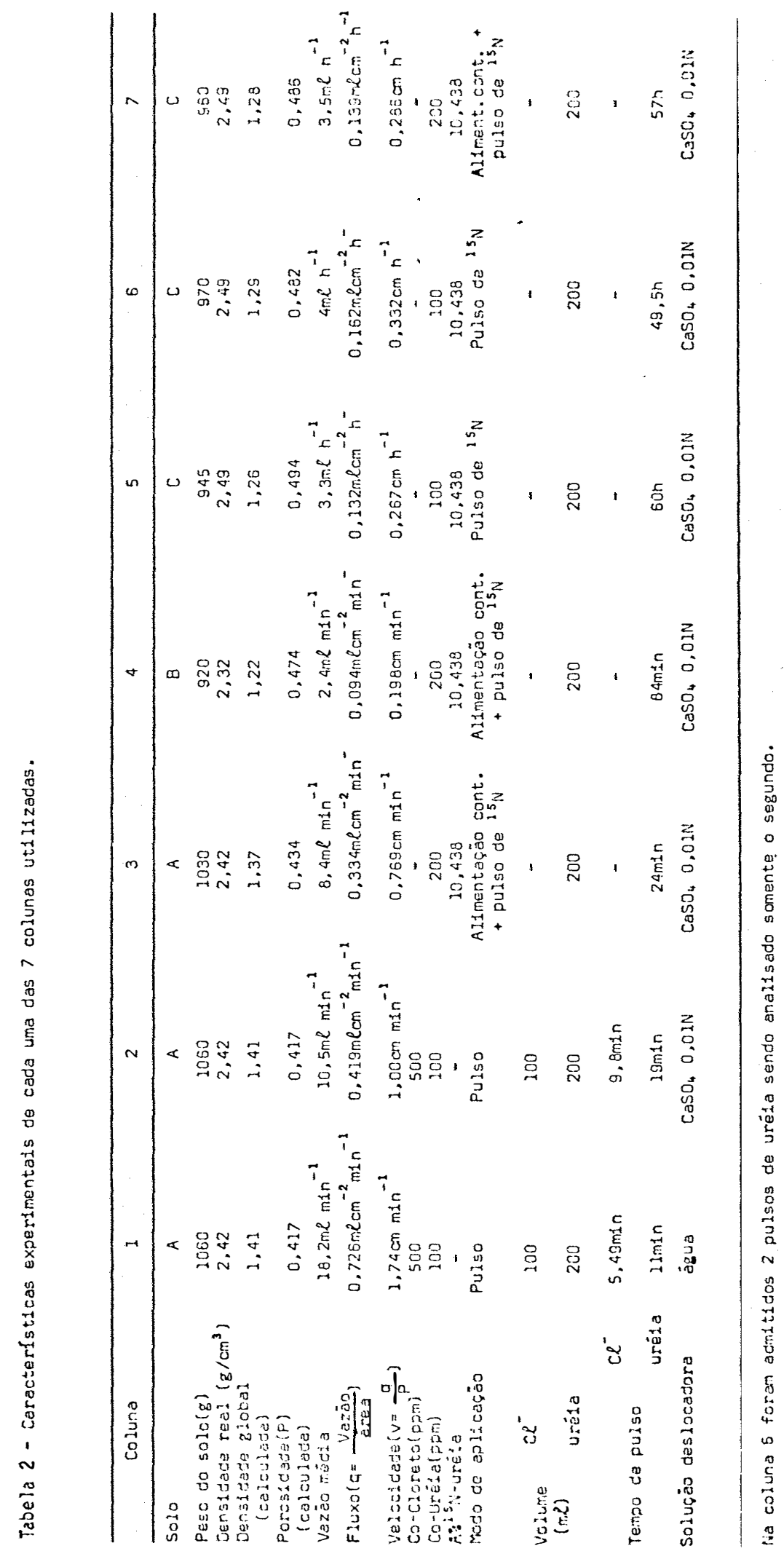


Diacetil Monoxima desenvolvido por DOUGLAS e BREMNER (1970). Para análise do $\mathrm{NH}_{4}^{+}$foi utilizado o método clássico de destilação por arraste de vapor em presença de MgO (BREMNER 1965a), e para análise de cloreto foi utilizä do o método colorimétrico do tiocianato férrico, por injeção em fluxo con tínuo, desenvolvido por RUZICKA et alii (1976).

Todas as colunas, com exceção às de números 1 e 2, foram seccionadas em 10 pedaços de $3 \mathrm{~cm}$ cada, ao final de cada experimento; as colunas 4 e 5 tiveram as sub-amostras, assim conseguidas, analisadas para determinação do nitrogênio total através da digestão de Kjeldhal, modificada para incluir nitrito e nitrato (BREMNER 1965b). Para as demais colu nas as sub-amostras de solo foram submetidas à extração por KCl 2N utilizado na proporção $1: 2,5$ (g solo/vol.kCl). Após agitação por 1 hora foi feita filtragem e posterior determinação de $\mathrm{NH}_{4}^{+}$trocável no filtrado; no solo residual foi feita a determinação do nitrogênio orgânico através do mesmo método de digestão utilizado para as colunas 4 e 5 .

Nos casos em que se utilizou uréia marcada, as amostras tị veram sua composição isotópica em ${ }^{15} \mathrm{~N}$ determinadas por espectrometria de massa, seguindo-se a metodologia descrita por TRIVELIN et alii (1973).

Na coluna de número 5 foram, na realidade, deslocados 2 pulsos, sendo analisado somente $02^{8}$ deles, por causa de problemas com 0 coletor de amostras durante a passagem do $1^{8}$ pulso.

\subsection{Modelo matemātico}

Considerando-se um processo de deslocamento miscível des- 
crito pela equação:

$$
\frac{\partial C}{\partial t}+\frac{\partial S}{\partial t}=D-\frac{\partial^{2} C}{\partial x^{2}}-v \frac{\partial C}{\partial x}-K C
$$

a solução analítica é dada pelas equações (52) e (57) para infiltração contínua de solutos e para infiltração de um pulso de soluto, respectivamente.

Para maior facilidade vamos reescrever a equação (52):

$\frac{C}{C 0}=\frac{1}{2}\left(\exp \left\{\frac{x}{2 D}\left(v-\sqrt{v^{2}+4 D K}\right)\right\} \operatorname{erfc}\left(\frac{x-t \sqrt{\left(\frac{V}{R}\right)^{2}+4 \frac{D}{R} \cdot \frac{K}{R}}}{\sqrt{4 \frac{D}{R} t}}+\right.\right.$

$+\exp \left\{\frac{x}{2 D}\left(v+\sqrt{v^{2}+4 D K}\right)\right\} \operatorname{erfc}\left(\frac{\left.x+t \sqrt{\left(\frac{v}{R}\right)^{2}+4 \frac{D}{R} \cdot \frac{K}{R}}\right)}{\sqrt{4 \frac{D}{R} t}}\right)$

para alimentação contínua, e reescrevê-la como:

$$
\frac{C}{C o}=\frac{1}{2} F(x, t)
$$

Para um pulso de soluto, e para $t>t_{1}$ (equação (57) teremos:

$$
\frac{C}{C_{0}}=\frac{1}{2}\left(F(x, t)-F\left\{x,\left(t-t_{1}\right)\right\}\right)
$$

Todos os símbolos já foram definidos anteriormente. 
Note-se que a equação (68) é apenas uma extensão da equação (66) e que para $R=1$ e $K=0$ teremos o caso mais simples de deslocamento miscível de um soluto que não sofre reações de adsorção e troca, e nem reações irreversíveis.

Desta maneira a equação (68) foi utilizada como equação ge. ral no desenvolvimento de um programa de computador para o cálculo das concentrações relativas do soluto em função do tempo de amostragem. computador utilizado foi um COMMODORE-PET, com linguagem BASIC de programação. Para o caso de um experimento de alimentação contínua, a não exis tência de um tempo de pulso $\left(t_{1}\right)$ acarreta a não utilização do termo $F\left|x,\left(t-t_{1}\right)\right|$ da equação (68).

Se $v, t_{1}, D, x, K$ e $R$ forem constantes, a equação (68) pode ser tomada como função somente do tempo de amostragem:

$$
\frac{C}{C o}=f(t)
$$

conseguindo-se assim uma sërie de concentrações relativas teóricas, ou curva de passagem teórica, que pode ser comparada com a curva de passagem experimental, para os mesmos tempos de amostragem.

Os valores de $t_{1}, v e \times$ são obtidos experimentalmente, e os valores de $\mathrm{D}, \mathrm{K}$ e R, serão estimados por ajuste de curvas através do método do quadrado mínimo, ou seja, serão aqueles para os quais a curva de passagem teórica obtida tem a menor soma de quadrados de desvios em re lação a curva de passagem experimental. 


\section{RESULTADOS E DISCUSSÃO}

Nas Tabelas 3 e 4 são apresentados os resultados das análí ses de $\mathrm{Cl}^{-}$e uréia, respectivamente, no efluente da coluna 1 . Na figura 2 estão apresentadas as curvas de passagem teóricas e os pontos experimen tais obtidos para os pulsos de $\mathrm{Cl}^{-}$e uréia nesta mesma coluna. A recuperação do $\mathrm{Cl}^{-}$aplicado, calculada pela integração da curva teórica, resultou em $100 \%$, enquanto que a calculada pelo volume e concentração de cada amostra resultou numa recuperação de 103\%. Esta pequena diferença observada pode ser atribuida a erros envolvidos no processo de análises químicas. Observa-se também uma concordância bastante grande entre a curva de passagem teórica e a experimental, sendo porém necessāria uma pequena alteração na velocidade, calculada em $1,74 \mathrm{~cm} . \mathrm{min} .^{-1}$ (Tabela 2), e sendo utilizada como $1,73 \mathrm{~cm} . \mathrm{min}^{-1}$. Esta pequena diferença é provavelmente devida a erro no cálculo da velocidade, em consequência de erro no cálculo da porosidade do solo. De qualquer maneira, convém salientar que a diferença causada na curva de passagem teórica é pequena, justificando desta maneira a utilização da velocidade de $1,74 \mathrm{~cm} / \mathrm{s}$. Os valores de velocidade e difusão utilizados para a obtenção da curva de passagem da uréia fo- 
Tabela 3 - Recuperação de $C \ell^{-}$no efluente da coluna 1. Solo: Podzólico VermeIho-Amarelo.

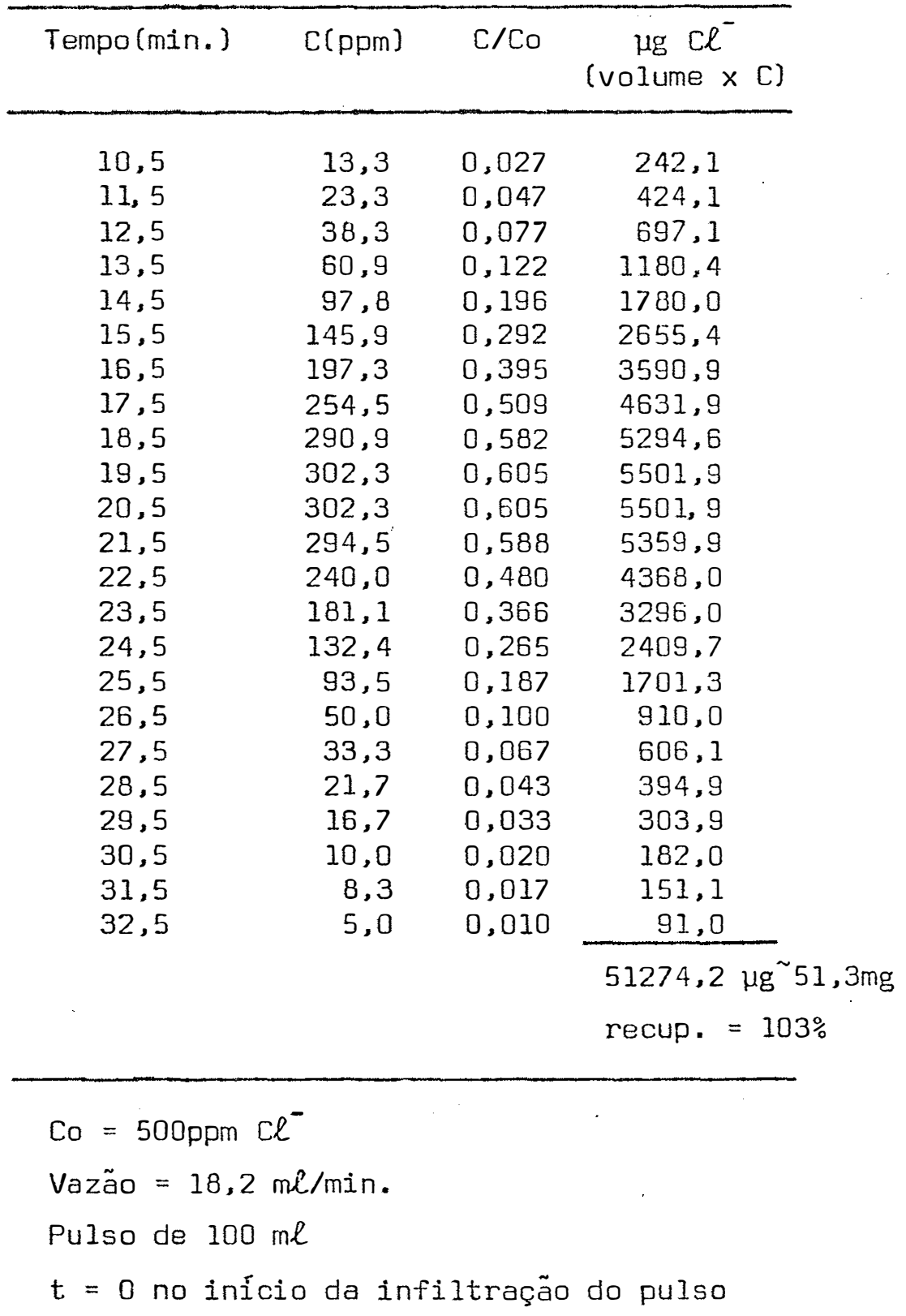


Tabela 4 - Recuperação de uréia no efluente da coluna 1. Solo: Podzólico Ver melho-Amarelo.

\begin{tabular}{|c|c|c|c|}
\hline $\begin{array}{l}\text { Tempo } \\
\text { (min.) }\end{array}$ & $\begin{array}{c}C \\
(p p m)\end{array}$ & C/Co & $\begin{array}{l}\mu \mathrm{g} \text { uréia } \\
\text { (volume } \times C\end{array}$ \\
\hline 15,5 & 4,9 & 0,049 & 89,2 \\
\hline 16,5 & 6,9 & 0,069 & 125,6 \\
\hline 17,5 & 9,6 & 0,096 & 174,7 \\
\hline 18,5 & 15,7 & 0,157 & 285,7 \\
\hline 19,5 & 23,5 & 0,235 & 427,7 \\
\hline 20,5 & 31,3 & 0,313 & 569,7 \\
\hline 21,5 & 40,0 & 0,400 & 728,0 \\
\hline 22,5 & 41,8 & 0,418 & 760,8 \\
\hline 23,5 & 53,1 & 0,531 & 966,4 \\
\hline 24,5 & 56,3 & 0,563 & 1024,7 \\
\hline 25,5 & 65,9 & 0,659 & 1199,4 \\
\hline 26,5 & 67,5 & 0,675 & 1228,5 \\
\hline 27,5 & 70,7 & 0,707 & 1286,7 \\
\hline 28,5 & 70,7 & 0,707 & 1286,7 \\
\hline 29,5 & 67,5 & 0,675 & 1228,5 \\
\hline 30,5 & 61,9 & 0,619 & 1126,6 \\
\hline 31,5 & 53,1 & 0,531 & 966,4 \\
\hline 32,5 & 46,6 & 0,466 & 848,1 \\
\hline 33,5 & 37,4 & 0,374 & 680,7 \\
\hline 34,5 & 28,9 & 0,289 & 526,0 \\
\hline 35,5 & 20,4 & 0,204 & 371,3 \\
\hline 36,5 & 17,0 & 0,170 & 309,4 \\
\hline 37,5 & 11,9 & 0,119 & 216,6 \\
\hline 38,5 & 8,5 & 0,085 & 154,7 \\
\hline 39,5 & 5,9 & 0,059 & 107,4 \\
\hline 40,5 & 4,2 & 0,042 & 76,4 \\
\hline \multirow[t]{2}{*}{41,5} & 3,4 & 0,034 & 61,9 \\
\hline & & & $\begin{array}{l}16827,7 \mu g \\
\text { recup. }=\end{array}$ \\
\hline
\end{tabular}

Co $=100 p p m$ uréia-N

Vazão $=18,2 \mathrm{ml} / \mathrm{min}$.

Pulso de $200 \mathrm{~m} 2$

$t=0$ no início da infiltração do pulso 




Figura 2 - Pontos experimentais e curvas de passagem teóricas para $\mathrm{Cl}^{-}$ e uréia na coluna 1. Solo: Podzólico Vermelho-Amarelo. 
ram os mesmos utilizados para a curva de $\mathrm{Cl}^{-}$. A não concordância temporal entre as curvas de $\mathrm{Cl}^{-}$e uréia indica haver retenção desta última no solo. Foi, portanto, necessária a utilização de um fator de retenção igual a 1,32 para que se obtivesse o melhor ajuste da curva de uréia. Foi também necessária a utilização de um fator de transformação igual a 0,006 min. $^{-1}$ e uma pequena diminuição no tempo de pulso, provavelmente devido a erro no volume de solução infiltrada. A recuperação de uréia no efluente foi de $84 \%$ quando calculada pelo volume e concentração das amostras, e de 87, 4\% quando calculada pela área da curva de passagem teórica. Esta diferença pode ser causada por erros experimentais ou pelo ajuste imperfeito da curva.

Nas Tabelas 5 e 6 são apresentados os resultados obtidos pa ra o $\mathrm{Cl}^{-}$e a uréia na coluna 2 , e na figura 3 são apresentadas as curvas teóricas e os pontos experimentais para esta mesma coluna. Foi novamente necessäria uma pequena alteração no valor da velocidade, de 1,00 cm/min. para o 0,985 cm/min. para a obtenção da melhor curva. A recuperação de $\mathrm{Cl}^{-}$foi igual a 91,4\% quando calculada pelo volume e concentração das amostras, e concentração das amostras, e de 90,3\% quando calculada pela in tegral da curva de passagem. Observa-se que a eluição do pulso de $\mathrm{Cl}^{-}$ não foi completa, o que explica as recuperações acima.

Os valores de velocidade e difusão utilizados para a obten ção da curva de passagem de $\mathrm{Cl}^{-}$foram também utilizados para a obtenção da curva de passagem de uréia. Como no caso da coluna 1, foi necessária a utilizaçãa de um fator de retenção $(R=1,20)$ e também de um fator de transformação $(K=0,006)$. A não utilização do fator de transformação ge 
Tabela 5 - Recuperação de $\mathrm{Cl}^{-}$no efluente da coluna 2. Solo: Podzólico

Vermeltho-Amarelo.

\begin{tabular}{|c|c|c|c|}
\hline $\begin{array}{l}\text { Tempo } \\
\text { (min.) }\end{array}$ & $C(\mathrm{ppm})$ & C/Co & $\begin{array}{l}\mu g \quad c l^{-} \\
\text {(volume } \times C \text { ) }\end{array}$ \\
\hline 19,5 & 9,8 & 0,020 & 102,9 \\
\hline 20,5 & 16,4 & 0,033 & 172,2 \\
\hline 21,5 & 24,6 & 0,049 & 258,3 \\
\hline 22,5 & 36,1 & 0,072 & 379,0 \\
\hline 23,5 & 47,5 & 0,095 & 498,8 \\
\hline 24,5 & 75,0 & 0,150 & 787,5 \\
\hline 25,5 & 94,6 & 0,189 & 993,3 \\
\hline 26,5 & 122,1 & 0,244 & 1282,0 \\
\hline 27,5 & 155,8 & 0,312 & 1636,3 \\
\hline 28,5 & 183,1 & 0,366 & 1922,6 \\
\hline 29,5 & 222,2 & 0,444 & 2333,1 \\
\hline 30,5 & 233,3 & 0,467 & 2449,7 \\
\hline 31,5 & 267,7 & 0,533 & 2800,3 \\
\hline 32,5 & 304,2 & 0,608 & 3194,1 \\
\hline 33,5 & 312,5 & 0,625 & 3281,3 \\
\hline 34,5 & 308,3 & 0,578 & 3237,1 \\
\hline 35,5 & 288,9 & 0,617 & 3033,5 \\
\hline 36,5 & 300,0 & 0,600 & 3150,0 \\
\hline 37,5 & 285,2 & 0,570 & 2994,6 \\
\hline 38,5 & 259,3 & 0,518 & 2722,6 \\
\hline 39,5 & 224,1 & 0,448 & 2353,1 \\
\hline 40,5 & 187,0 & 0,374 & 1963,5 \\
\hline 41,5 & 153,2 & 0,306 & 1608,6 \\
\hline 42,5 & 135,1 & 0,270 & 1418,5 \\
\hline 43,5 & 107,8 & 0,216 & 1142,4 \\
\hline
\end{tabular}

$\mathrm{Co}_{\mathrm{O}}=500 \mathrm{ppm}$

Vazão $=10,5 \mathrm{~m} \ell / \mathrm{min}$.

Pulso de $100 \mathrm{~m} \ell$

$t=0$ no início da infiltração do pulso 
Tabela 6 -Recuperaçāo de uréia no efluente da coluna 2. Solo: Podzólico Ver melho-Amarelo

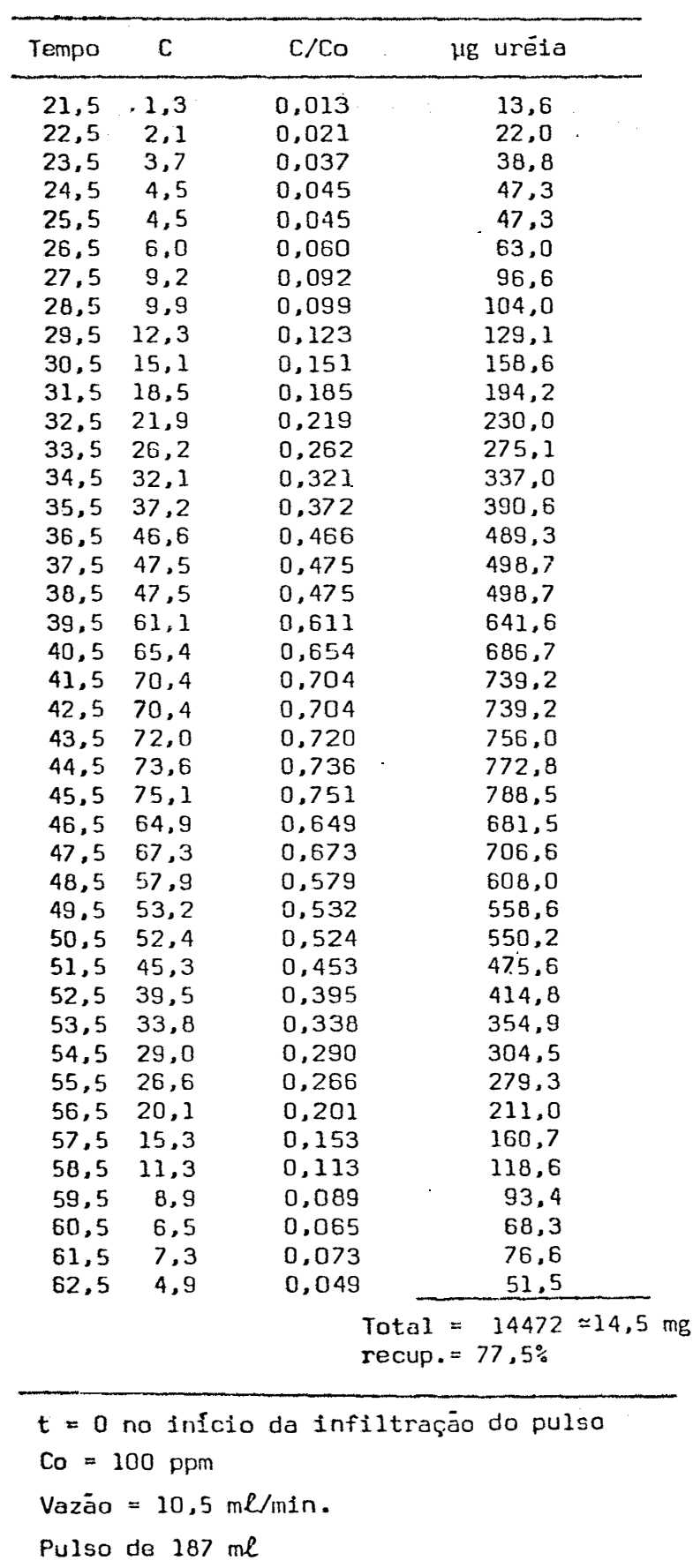




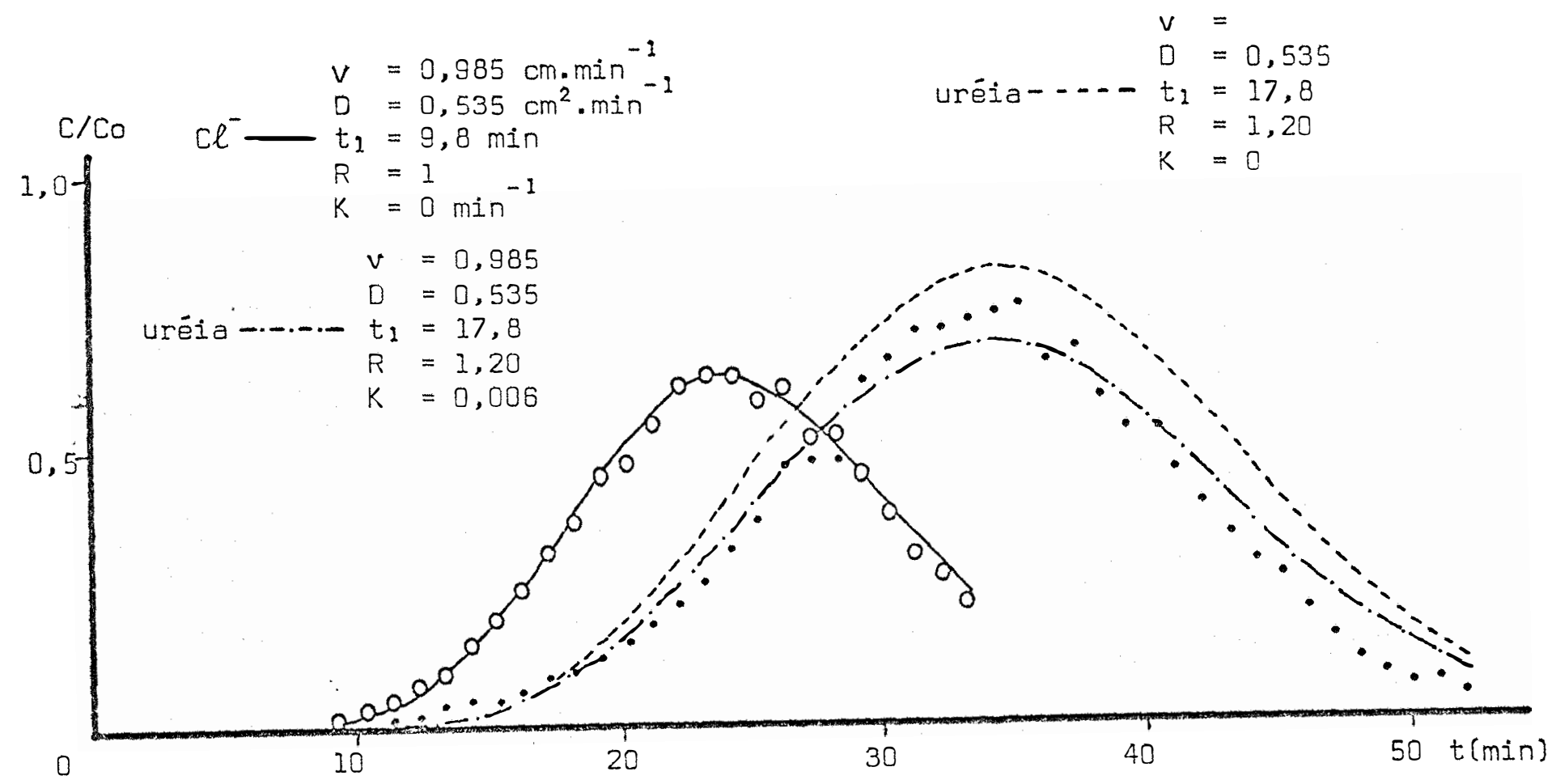

Figura 3 - Pontos experimentais e curvas de passagem teóricas para cl- e uréia na coluna 2. Solo: Podzólico Vermelho-Amarelo. 
ra uma curva completamente desajustada aos pontos experimentais, como pode ser visto na figura 3; houve também necessidade de se alterar o tempo de infiltração do puiso, de 19,0 para 17,8 min.. Como no caso da coluna 1, houve provavelmente erro no volume de solução infiltrada. Será então considerado, para cálculo da recuperação, que foram infiltrados $187 \mathrm{~m} \ell$ da solução de uréia, correspondendo a $18,7 \mathrm{mg}$ de uréia-N aplicadas.

A recuperação de uréia no efluente, calculada pelo volume e concentração das amostras, foi de $77,5 \%$ (Tabela 6), e a calculada pela área da curva de passagem teórica foi de 81,2\%. Esta diferença pode ser explicada pelo ajuste imperfeito da curva de passagem teórica aos pontos experimentais.

Na figura 4 são apresentadas as curvas de passagem teóricas e os pontos experimentais obtidos para a coluna 3. Note-se que nesta coluna não foi utilizado o íon $\mathrm{Cl}^{-}$para a determinação da dispersão. Note-se também que foi necessária a utilização de uma velocidade menor que a calculada (Tabela 2), e que a alteração efetuada é bem maior que nos ca sos das colunas 1 e 2 . Neste caso, esta alteração mais drástica da velocidade indica haver a retenção de uréia também nesta coluna. Lembrando a equação (34), vemos que no caso de haver retenção no solo, a velocidade e dispersão ficam divididas pelo fator de retenção. Teríamos, então, neste caso:

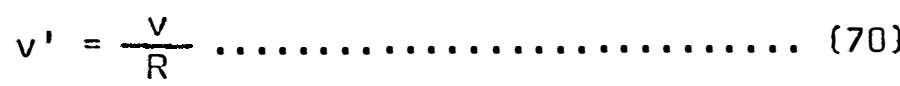

ou

$$
0,68=\frac{0,769}{R}
$$


e portanto

$$
R=1,13
$$

A validade desta marieira de se calcular $R$ é atestada pelo fato de que a utilização de $v=0,769 \mathrm{~cm} \cdot \mathrm{min} . .^{-1}, 0=0,72 \times 1,13=0,81$ $\mathrm{cm}^{2} \min .^{-1}$ e $\mathrm{K}=0$ resultaria numa curva de passagem que tem o valor de $c / C_{0}=0,5$ para o tempo que representa 1 volume de poros de efluente, e que seria equivalente a curva de passagem para o ín $\mathrm{CL}^{-}$.

A curva de passagem teórica para alimentação contínua de uréia foi obtida utilizando-se um fator de transformação $K=0 \mathrm{~min} .^{-1} \mathrm{com}$ excelente ajuste para os pontos iniciais. Nota-se, porém, que os pontos experimentais e a curva teórica estão desajustados a partir do tempo $t=$ $160 \operatorname{min.}$

Deste tempo em diante os pontos experimentais estão abaixo da curva teórica, indicando haver portanto hidrólise da uréia. A introdu ção e o tempo de duração do pulso de uréia marcada nesta coluna está indi cada pelas duas setas verticais na curva de alimentação contínua da figura 4. A curva de passagem foi construida considerando-se $t=0$ no início da infiltração do pulso. Observa-se que a curva de passagem construida com $K=0$ min. ${ }^{-1}$ está bastante desajustada em relação aos pontos experimentais. O melhor ajuste foi obtido quando foi utilizado um valor de $\mathrm{K}=$ $0,003 \mathrm{~min}^{-1}$, confirmando a existência de hidrólise da uréia nesta coluna. A recuperação de uréia - ${ }^{15} \mathrm{~N}$ calculada com base na área da curva de passagem téórica foi de $87,7 \%$. 


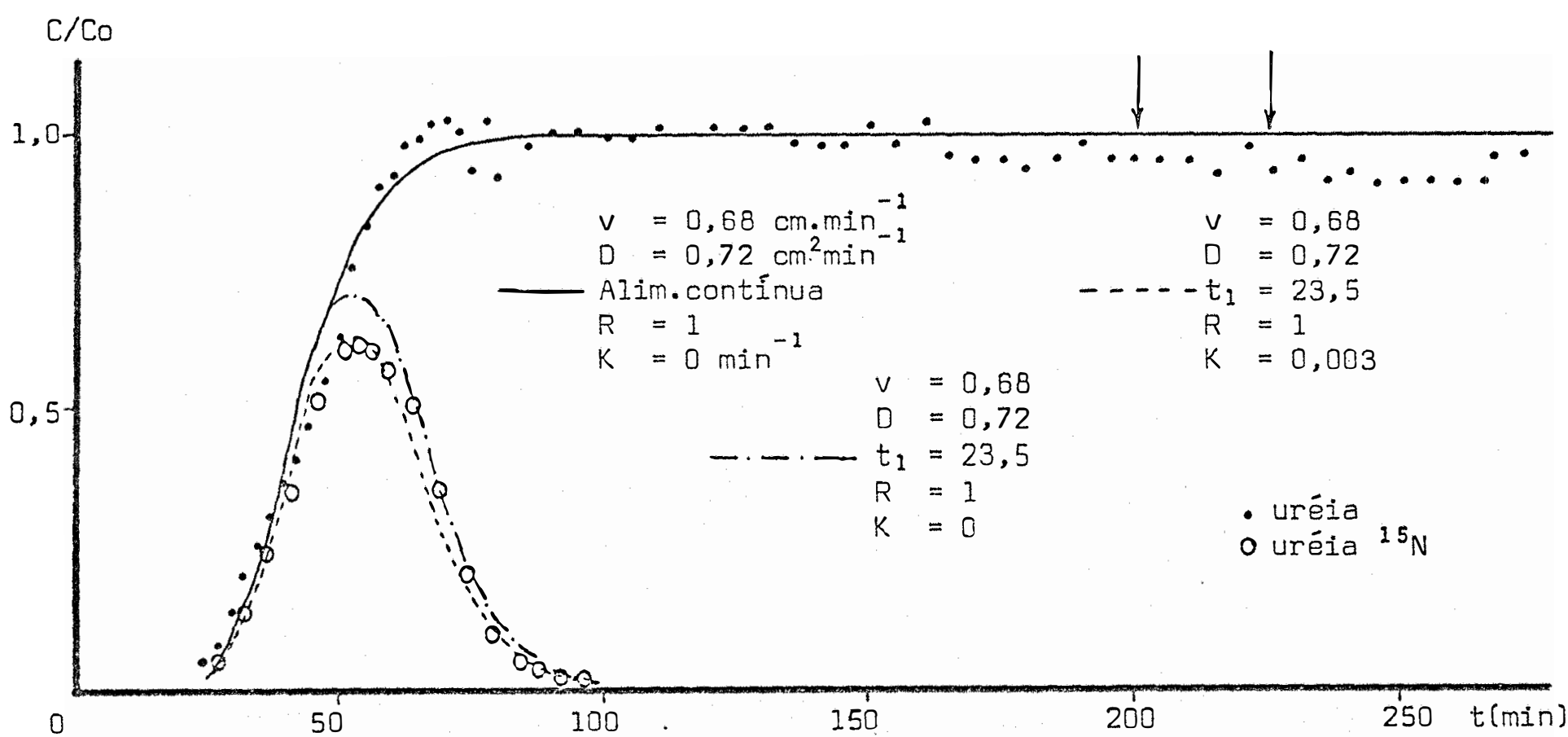

Figura 4 - Pontos experimentais e curvas de passagem teóricas para alimentação contínua e pulso de uréia na coluna 3. Solo: Podzólico Vermelho-Amarelo. 
Para esta coluna, no tempo $t=300 \mathrm{~min}$., foram retiradas, com seringas de lme e através de furos previamente feitos, 5 amostras da solução do solo, a cada $5 \mathrm{~cm}$ de profundidade. Estas amostras foram anali sadas para determinação da concentração de uréia, e os resultados são apresentados na figura 5. A distribuição teórica nesta figura foi obtida através da equação (52), considerando-se constante o tempo e variando-se a profundidade. Nota-se que existe uma boa concordāncia entre os valores experimentais e a distribuição teórica obtida com um fator de transformação $K=0,002 \mathrm{~min} .^{-1}$, que embora diferente do fator utilizado para o ajus te da curva de passagem do pulso de uréia - ${ }^{15} \mathrm{~N}\left(K=0,003 \mathrm{~min} .^{-1}\right.$ - $\mathrm{figu}^{-}$ ra 4), acarretaria uma diferença de somente $3,5 \%$ na recuperação de uréia no efluente. Esta diferença está muito provavelmente dentro do erro expe rimental da própria determinação quantitativa da uréia.

Na Tabela 7 são apresentados os resultados das análises de $\mathrm{NH}_{4}^{+}$no efluente da coluna 3. Foram analisadas somente as amostras finais do experimento, onde os dados indicam uma recuperação de $1,67 \mathrm{mg}$ de $\mathrm{N}^{1}{ }^{5} \mathrm{~N}$, equivalente a $4,2 \%$ do total aplicado. Os dados também indicam que amostras anteriores à amostra 211 continham $\mathrm{NH}_{4}^{+}-{ }^{15} \mathrm{~N}$, não tendo sido, no entanto, analisadas.

Nas Tabelas 8 e 9 encontram-se os resultados de $\mathrm{NH}_{4}^{+}$tro cável e N-orgánico do solo da coluna 3. Observa-se que as camadas inferiores apresentam maior enriquecimento em ${ }^{15} \mathrm{~N}$ para $\mathrm{NH}_{4}^{+}$trocável, o que es tá em concordáncia com os resultados da Tabela 7, onde a última amostragem tem um enriquecimento em ${ }^{15} \mathrm{~N}$ bastante semelhante ao enriquecimento da camada 27-30 cm do solo (Tabela B). Na Tabela 9 observa-se que muito pou 


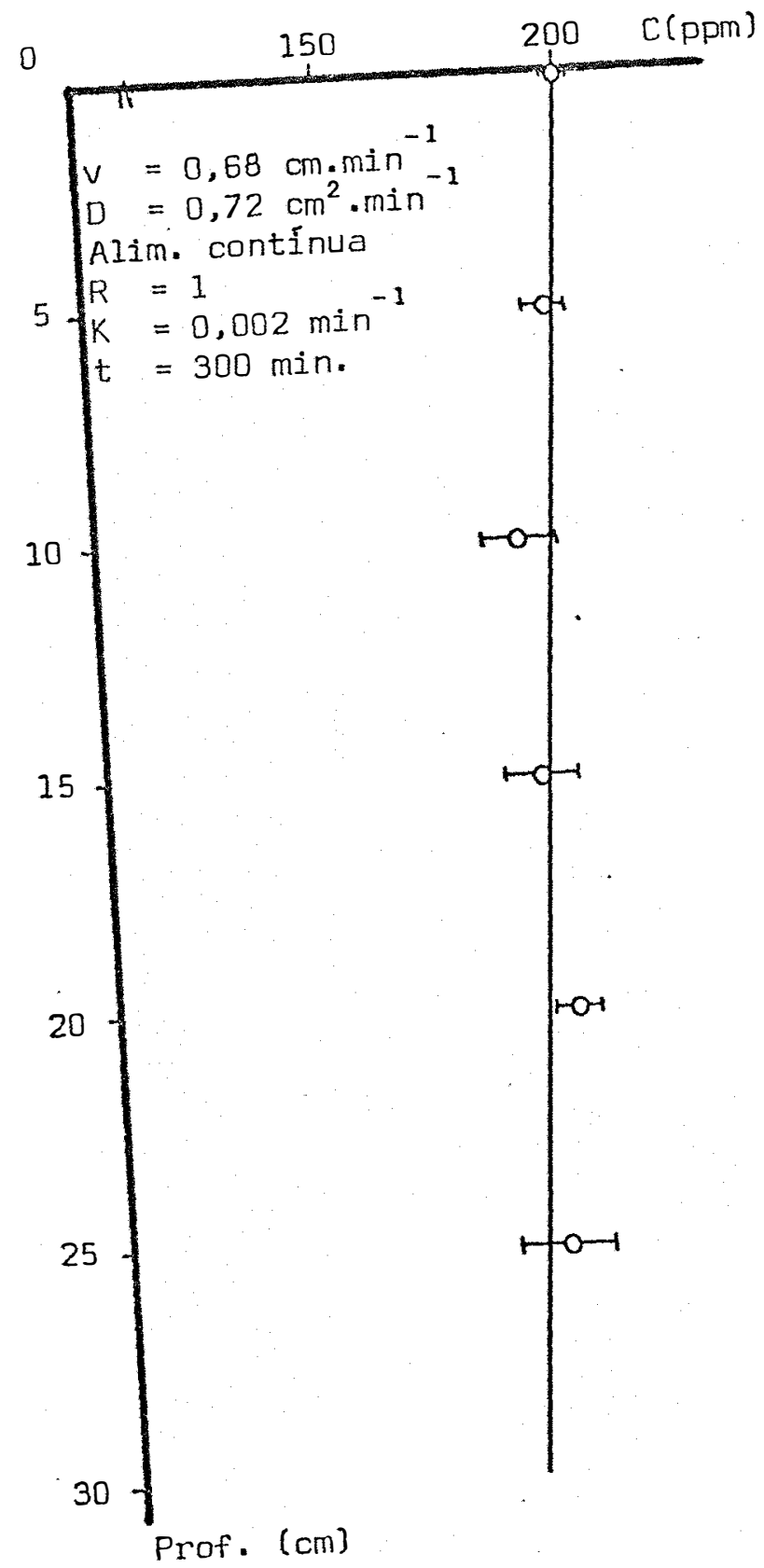

Figura 5 - Distribuições experimental e teórica de uréia ao longo da coluna 3. Solo: Podzólico Vermelho-Amarelo. 
Tabela 7 - Recuperação de $\mathrm{NH}_{4}^{+}-{ }^{15} \mathrm{~N}$ no efluente da coluna 3. Solo: Podzólico Vermelho-Amarelo.

\begin{tabular}{|c|c|c|c|c|c|}
\hline$A M$ & $\begin{array}{l}\text { Volume } \\
(\mathrm{m} \ell)\end{array}$ & $C(p p m)$ & $A \%^{15} \mathrm{~N}$ & $\% N P U$ & $\mathrm{mg} N P U$ \\
\hline 211 a 218 & 85 & \multirow{6}{*}{$16 \pm 4$} & 3,932 & 35,4 & 0,48 \\
\hline 219 a 226 & 85 & & 2,740 & 23,5 & 0,32 \\
\hline 227 a 236 & 106 & & 2,186 & 18,0 & 0,30 \\
\hline 237 a 246 & 106 & & 2,398 & 20,2 & 0,34 \\
\hline \multirow[t]{2}{*}{247 a 252} & 64 & & 2,609 & 22,2 & 0,23 \\
\hline & & & & Total & 1,67 \\
\hline
\end{tabular}

NPU = nitrogênio proveniente da uréia

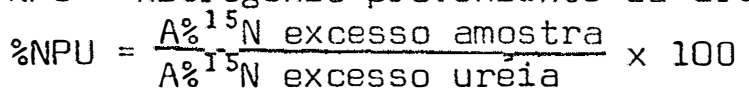

Tabela 8 - Distribuição e recuperação de $\mathrm{NH}_{4}^{+}-{ }^{15} \mathrm{~N}$ trocável no solo da coluna 3. Solo Podzólico Vernelho-Amarelo.

\begin{tabular}{ccccc}
\hline $\begin{array}{c}\text { Camada } \\
(\mathrm{cm})\end{array}$ & $\begin{array}{c}\mathrm{NH}_{4}^{+} \text {Total } \\
(\mathrm{mg})\end{array}$ & $\mathrm{A} \%{ }^{15} \mathrm{~N}$ & $\% \mathrm{NPU}$ & $\mathrm{mg} \mathrm{NPU}$ \\
\hline 0 a 3 & 1,3 & 0,447 & 0,8 & 0,01 \\
3 a 6 & 2,1 & 0,414 & 0,5 & 0,01 \\
6 a 9 & 1,4 & 0,440 & 0,7 & 0,01 \\
9 a 12 & 0,9 & 0,499 & 1,3 & 0,01 \\
12 a 15 & 0,9 & 0,667 & 3,0 & 0,03 \\
15 a 18 & 1,0 & 0,918 & 5,5 & 0,06 \\
18 a 21 & 1,5 & 1,154 & 7,9 & 0,12 \\
21 a 24 & 1,5 & 1,441 & 10,7 & 0,16 \\
24 a 27 & 1,3 & 2,197 & 18,2 & 0,24 \\
27 a 30 & 1,3 & 2,473 & 20,9 & 0,27 \\
\hline
\end{tabular}


co $\mathrm{N}^{15} \mathrm{~N}$ permanece no solo numa forma não trocável. O total de nitrogênio marcado que restou no solo após o experimento é dado pela soma dos to tais das Tabelas 8 e 9 , ou seja, $1,17 \mathrm{mg}$, equivalente a $2,9 \%$ do total aplicado.

Tabela 9 - Distribuição e recuperação de ${ }^{15} \mathrm{~N}$ - orgânico no solo da coluna 3. Digestão de Kjeldhal após ex tração com $\mathrm{KCl} 2 \mathrm{~N}$.

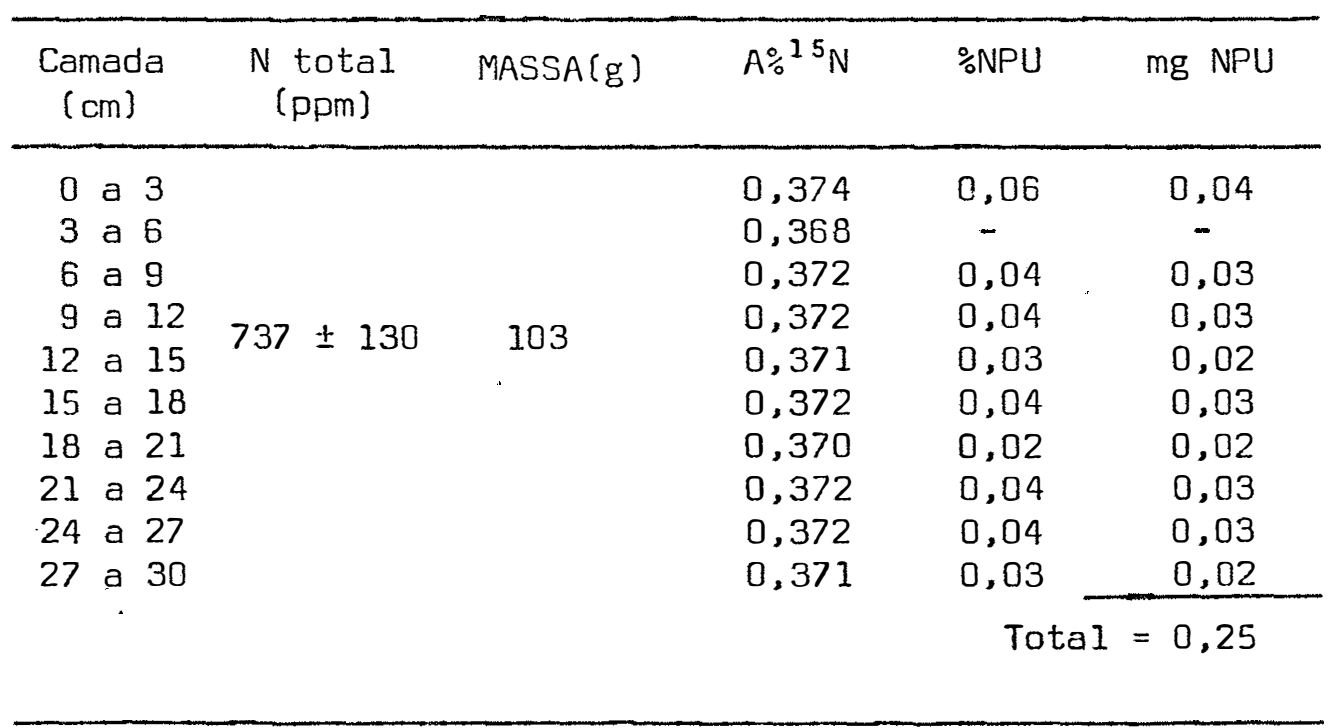

Na figura 6 são apresentados os pontos experimentais e as curvas de passagem teóricas, tanto para alimentação contínua, como para o pulso de uréia - ${ }^{15} \mathrm{~N}$ da coluna 4. O início da aplicação, e o tempo de dü ração do pulso de uréia marcada é indicado na figura pelas duas setas ver ticais na curva de alimentação contínua. Nesta coluna também não foi utị lizado cloreto para obtenção da dispersão. Cálculo semelhante do efetuado para a coluna 3 (equação 70 ) resultaria num fator de retenção $R=1,12$, 


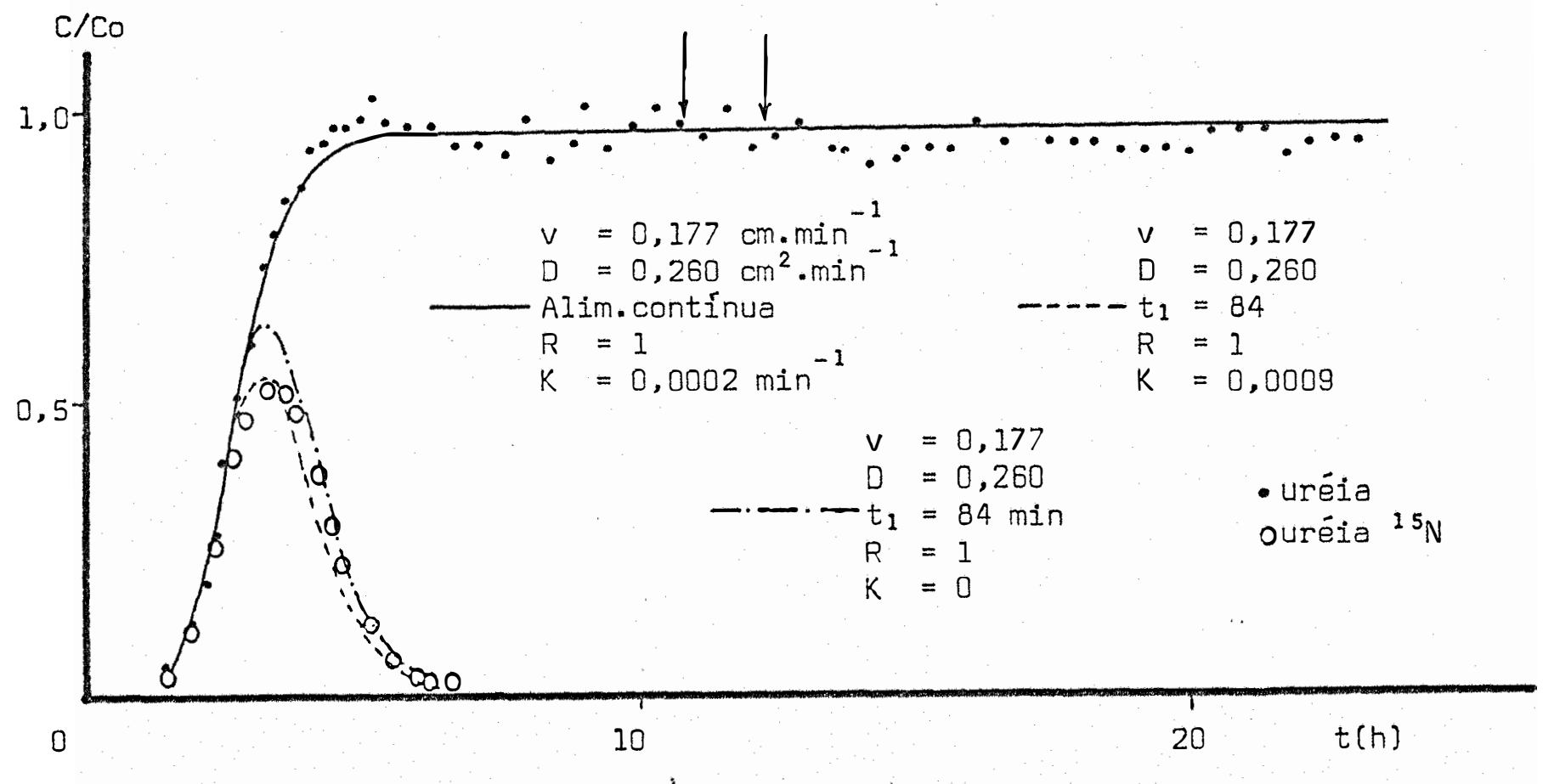

Figura 6 - Pontos experimentais e curvas de passagem teóricas para alimentação contínua e pulso de uréia na coluna 4. Solo: Latossolo Amarelo. 
sendo, então, $D=0,29 \mathrm{~cm}^{2} \mathrm{~min}^{-1}$. Note-se a diferença entre os fatores de transformação utilizados para obtenção das curvas de alimentação contí nua e pulso, porém é também evidente uma queda na concentração do efluente logo após a infiltração do pulso de uréia marcada, o que explicaria es ta diferença. Na figura 7 estão apresentados os pontos experimentais de 4 amostras colhidas a cada $5 \mathrm{~cm}$ no perfil da coluna no tempo de $1442 \mathrm{~min}$. A curva sólida representa a distribuição teórica para um fator de transfor mação $K=0,0009 \mathrm{~min}^{-1}$, e observa-se que existe uma boa concordância entre os pontos experimentais e teóricos, confirmando desta maneira a utili zação deste mesmo fator no ajuste da curva de passagem para o pulso de uréia marcada. A recuperação de uréia - ${ }^{15} \mathrm{~N}$ calculada pela área da curva teórica de melhor ajuste resultou em $34,3 \mathrm{mg}$, equivalente a $85,8 \%$ do total aplicado.

Na Tabela 10 estão apresentados os resultados obtidos na análise de $\mathrm{NH}_{4}^{+}-\mathrm{N}$ no efluente da coluna 4. Foram recuperadas 4,47 mg da uréia marcada na forma $\mathrm{NH}_{4}^{+}-\mathrm{N}$ no efluente da coluna, o que equivale a 11,2\% do total aplicado. Nas Tabelas 11 e 12 são mostrados os resultados para $\mathrm{NH}_{4}^{+}-\mathrm{N}$ trocável e $\mathrm{N}$-orgànico do solo, respectivamente, para esta mesma coluna. Note-se que muito pouco nitrogênio proveniente da uréia marca da permaneceu na coluna ao término do experimento. o total de nitrogênio proveniente da uréia marcada que permaneceu no solo no final do experimen to soma $0,286 \mathrm{mg}$, equivalente a $0,7 \%$ do total aplicado.

Na Tabela 13 são apresentados os resultados obtidos para recuperação de uréia no efluente da coluna 5. A recuperação de uréia cal culada com base na concentração e volume de cada amostra resultou em 6,9l 


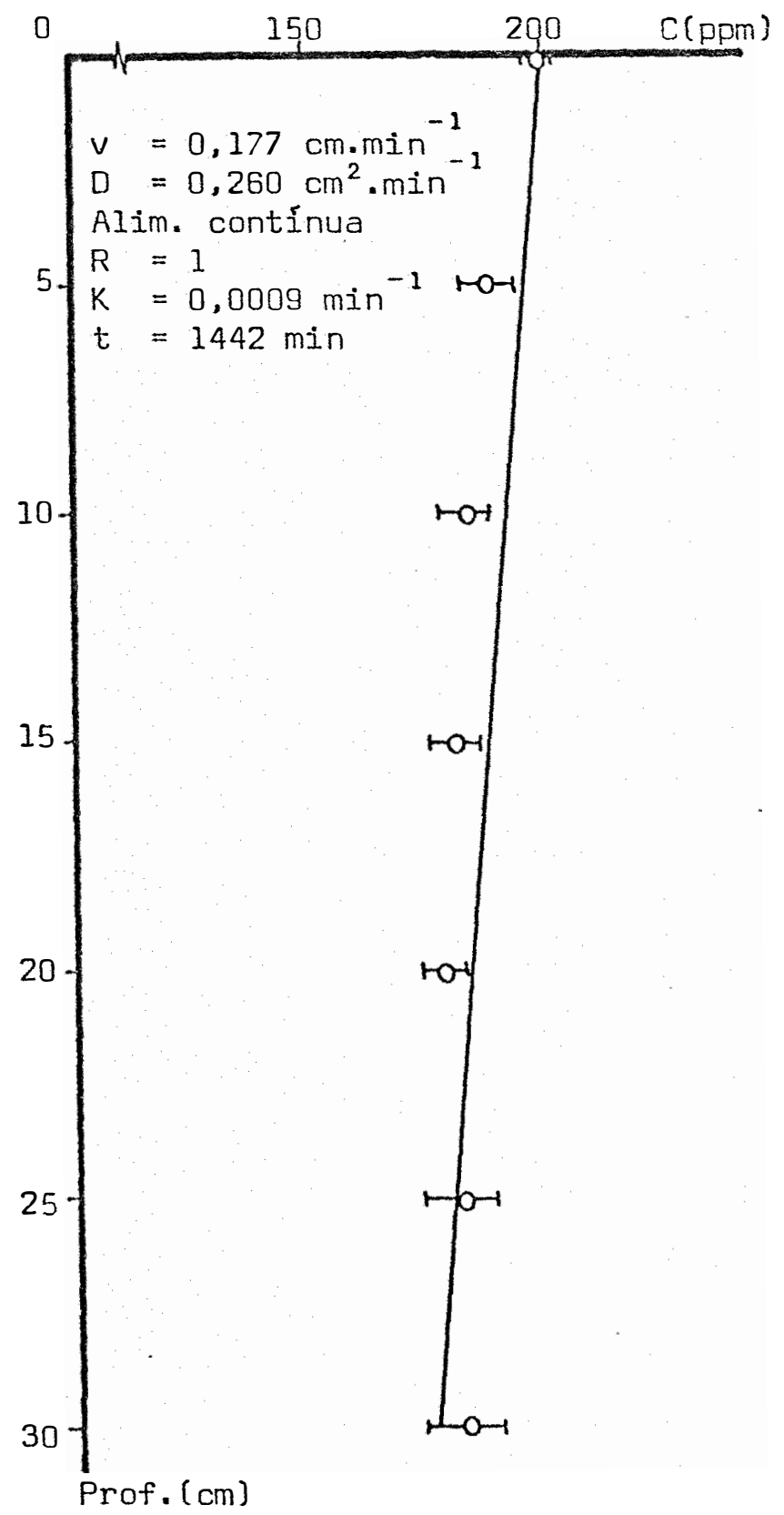

Figura 7 - Distribuições experimental e teórica de uréia ao longo da coluna 4. Solo: Latossolo Amare10. 
Tabela 10 - Recuperação de $\mathrm{NH}_{4}^{+}-{ }^{15} \mathrm{~N}$ no efluente da coluna 4. Solo: Latossolo Amarelo.

\begin{tabular}{|c|c|c|c|c|c|}
\hline Amostra & $\begin{array}{c}\text { Volume } \\
(\mathrm{ml})\end{array}$ & $c(p p m)$ & $A \%{ }^{15} \mathrm{~N}$ & \%NPU & mg NPU \\
\hline 106 a 110 & 76,5 & & 0,442 & 0,7 & 0,01 \\
\hline 111 a 114 & 61,0 & & 0,667 & 3,0 & 0,03 \\
\hline 115 a 118 & 61,0 & & 1,232 & 8,6 & 0,09 \\
\hline 120 a 128 & 153,0 & & 2,840 & 24,5 & 0,66 \\
\hline 129 a 136 & 122,5 & & 4,120 & 37,3 & 0,80 \\
\hline 137 a 144 & 122,5 & & 3,398 & 30,1 & 0,64 \\
\hline 145 a 152 & 122,5 & & 2,334 & 19,5 & 0,42 \\
\hline 153 a 173 & 306,0 & $17,5 \pm 3$ & 2,032 & 16,5 & 0,88 \\
\hline 174 a 180 & 122,5 & & 1,838 & 14,6 & 0,31 \\
\hline 181 a 188 & 122,5 & & 1,516 & 11,4 & 0,24 \\
\hline 189 a 196 & 122,5 & & 1,21 & 8,4 & 0,18 \\
\hline 197 a 202 & 92 & & 0,947 & 5,8 & 0,09 \\
\hline 203 a 208 & 92 & & 0,755 & 3,8 & 0,06 \\
\hline 209 a 214 & 92 & & 0,607 & 2,4 & 0,04 \\
\hline \multirow[t]{2}{*}{215 a 221} & 92 & & 0,508 & 1,4 & 0,02 \\
\hline & & & & Tot & $=4,47$ \\
\hline
\end{tabular}

Tabela 11 - Distribuição e recuperação de $\mathrm{NH}_{4}^{+}-{ }^{15} \mathrm{~N}$ trocável para o solo da coluna 4. Solo: Latossolo Amare10.

\begin{tabular}{|c|c|c|c|c|}
\hline $\begin{array}{c}\text { Camada } \\
(\mathrm{cm})\end{array}$ & $\mathrm{NH}_{4}^{+}-\mathrm{N}(\mathrm{mg})$ & $A \%{ }^{15} \mathrm{~N}$ & $\because N P U$ & 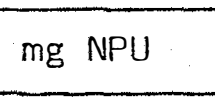 \\
\hline $\begin{array}{rll}0 & \text { a } & 3 \\
3 & \text { a } & 6 \\
6 & \text { a } & 9 \\
9 & \text { a } & 12 \\
12 & \text { a } & 15 \\
15 & \text { a } & 18 \\
18 & \text { a } & 21 \\
21 & \text { a } & 24 \\
24 & \text { a } & 27 \\
27 & \text { a } & 30\end{array}$ & $\begin{array}{l}1,36 \\
1,19 \\
1,41 \\
1,87 \\
1,37 \\
1,87 \\
1,47 \\
1,60 \\
1,97 \\
2,13\end{array}$ & $\begin{array}{l}0,378 \\
0,375 \\
0,373 \\
0,374 \\
0,373 \\
0,380 \\
0,382 \\
0,385 \\
0,395 \\
0,458\end{array}$ & $\begin{array}{l}0,08 \\
0,07 \\
0,05 \\
0,06 \\
0,05 \\
0,12 \\
0,14 \\
0,17 \\
0,27 \\
0,89\end{array}$ & $\begin{array}{l}0,001 \\
0,001 \\
0,001 \\
0,001 \\
0,001 \\
0,002 \\
0,002 \\
0,003 \\
0,005 \\
0,019 \\
\end{array}$ \\
\hline & & & \multicolumn{2}{|c|}{ Total $=0,036 \mathrm{mg}$} \\
\hline
\end{tabular}


mg, equivalente a $34,6 \%$ do total aplicado.

Tabela 12 - Distribuição e recuperação de ${ }^{15} \mathrm{~N}$-orgânico no solo da coluna 4. Digestão de Kjeldhal após extração com KCl 2N. Solo: Latossolo Amarelo

\begin{tabular}{|c|c|c|c|c|c|}
\hline $\begin{array}{l}\text { Camada } \\
:(\mathrm{cm})\end{array}$ & $\begin{array}{c}N \text { total } \\
(\mathrm{ppm})\end{array}$ & $\operatorname{MASSA}(g)$ & $A \% 15 \mathrm{~N}$ & ¿NPU & mg NPU \\
\hline $\begin{array}{rll}0 & a & 3 \\
3 & a & 6 \\
6 & a & 9 \\
9 & \text { a } & 12 \\
12 & a & 15 \\
15 & a & 18 \\
18 & \text { a } & 21 \\
21 & a & 24 \\
24 & a & 27 \\
27 & \text { a } & 30\end{array}$ & \multirow[t]{2}{*}{$767 \pm 140$} & \multirow[t]{2}{*}{92} & $\begin{array}{l}0,372 \\
0,370 \\
0,373 \\
0,370 \\
0,372 \\
0,372 \\
0,372 \\
0,371 \\
0,371 \\
0,371\end{array}$ & $\begin{array}{l}0,04 \\
0,02 \\
0,05 \\
0,02 \\
0,04 \\
0,04 \\
0,04 \\
0,03 \\
0,03 \\
0,03\end{array}$ & $\begin{array}{l}0,03 \\
0,01 \\
0,04 \\
0,01 \\
0,03 \\
0,03 \\
0,03 \\
0,02 \\
0,02 \\
0,02 \\
\end{array}$ \\
\hline & & & & Tota & $=0,25$ \\
\hline
\end{tabular}

Na figura 8 são apresentados os pontos experimentais e as curvas de passagem teóricas para uréia na coluna 5. Note-se que, para ob tenção da curva que melhor se ajusta aos pontos experimentais, foi necessária uma alteração bastante grande no tempo de infiltração do pulso, que experimentalmente foi de $60 \mathrm{~h}$ (Tabela 2), o que leva à conclusão de que o modelo matemático proposto é falho para descrever o deslocamento miscível de uréia neste solo. O fato de se conseguir um ajuste razoavelmente bom entre os pontos experimentais e a curva teórica para valores de $v=0,216$ om $\mathrm{h}^{-1}, D=0,07 \mathrm{~cm}^{2} \mathrm{~h}^{-1}, t_{1}=42 \mathrm{~h}$ e $\mathrm{K}=0,003 \mathrm{~h}^{-1}$, somente indica que é possível o ajuste de 4 parâmetros para obtenção de uma melhor curva, porém são somente.valores aproximados dos parâmetros reais deste solo. E 
Tabela 13 - Recuperação de uréia no efluente da coluna 5. Solo: de várzea.






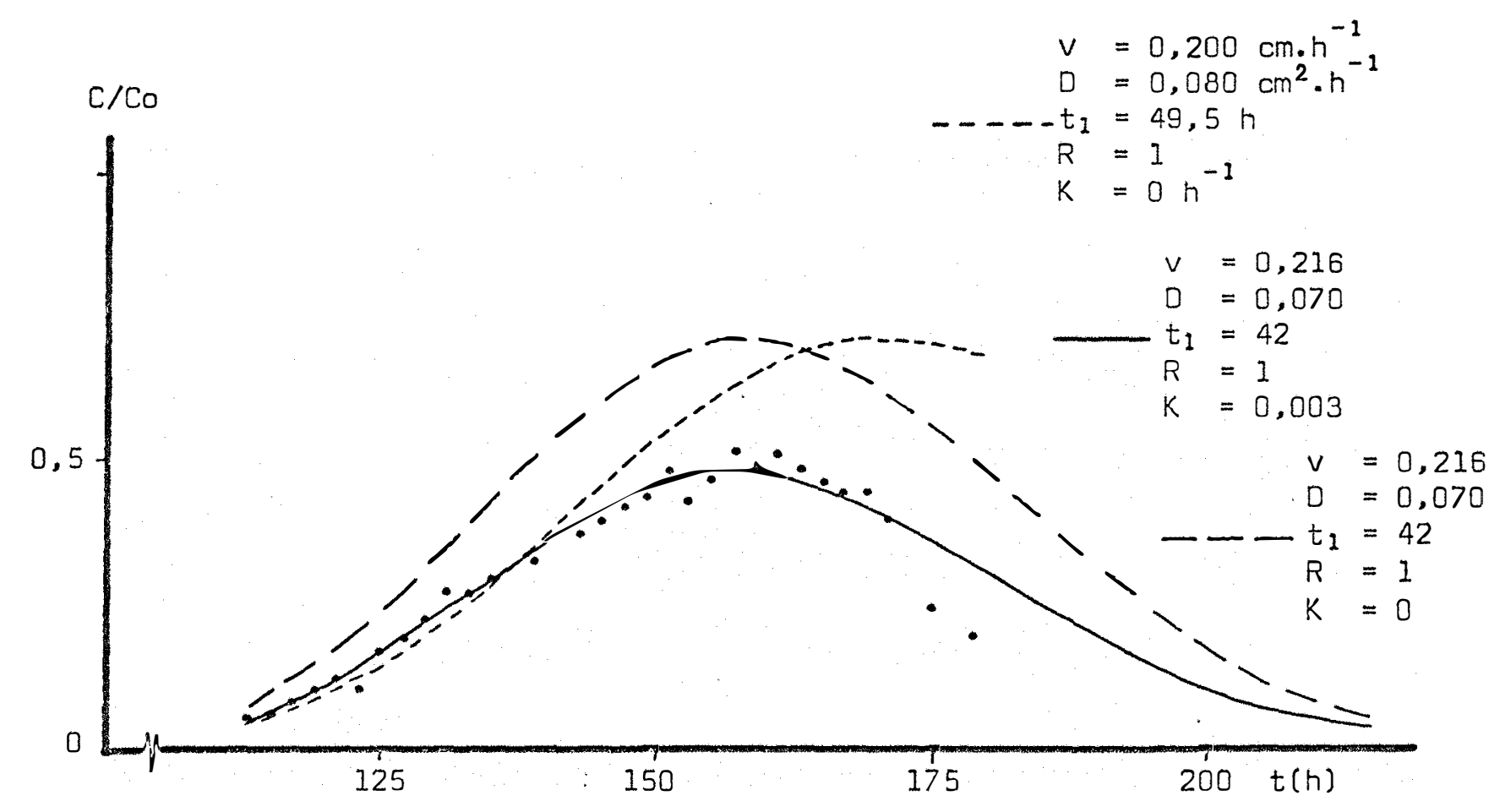

Figura 8 - Pontos experimentais e curvas de passagem teóricas para pulso de uréia na coluna 5. Solo de várzea. 
bem provável que o fator de transformação, ou seja a atividade da urease esteja variando com o tempo.

De qualquer maneira, a curva que melhor se ajusta aos dados experimentais pode ser utilizada para calcular a recuperação da uréia no efluente, desde que seja utilizado para termo de comparação o valor re al de tempo de pulso; calculada desta maneira, a recuperação de uréia no efluente desta coluna resultou em $34,5 \%$, valor praticamente igual ao dado na tabela 13.

Os resultados das análises de $\mathrm{N}$ total e ${ }^{15} \mathrm{~N}$ nas amostras do solo da coluna 5, ao término deste experimento, são mostrados na Tabela 14. Nesta coluna não foi feita extração das amostras com KCl $2 N$, analisando-as como um todo. A observação conjunta da distribuição de ${ }^{15} \mathrm{~N}$ no perfil da coluna e curva de passagem experimental da figura 8 indica que o aumento da concentração de ${ }^{15} \mathrm{~N}$ nas camadas inferiores é devido à uréia que ainda não deixou a coluna, sendo, portanto, a marcação das cama das superiores devido ao $\mathrm{NH}_{4}^{+}-{ }^{15} \mathrm{~N}$ retido no solo. Foram recuperados no solo da coluna 5, após o término do experimento, 14,47 mg de $\mathrm{N}$, equivalen te a $72,3 \%$ do total aplicado. Análises de $\mathrm{NH}_{4}^{+}$no efluente desta coluna revelaram que quantidades desprezíveis de amônio deixaram a coluna.

Na coluna 6 foram admitidos dois pulsos de uréia marcada. Problemas com o coletor automático de frações durante a passagem do $1^{\circ}$ pulso não permitiram sua análise. Será considerado, no entanto, para ba lanço de $N$, a admissão de $40 \mathrm{mg}$ de $N-{ }^{15} \mathrm{~N}$, que corresponde ao total dos dois pulsos. O intervalo de tempo entre o início de infiltração do $I^{8}$ 
pulso e o início de infiltração do $2^{\circ}$ pulso foi de 10 dias ou 240 horas,a proximadamente.

Tabela 14 - Distribuição e recuperação de ${ }^{15} \mathrm{~N}$ no solo da coluna 5. Solo de várzea.

\begin{tabular}{|c|c|c|c|c|c|}
\hline $\begin{array}{c}\text { Camada } \\
(\mathrm{cm})\end{array}$ & $\begin{array}{c}\mathrm{N} \text { total } \\
\text { (ppm) }\end{array}$ & $\operatorname{MASSA}(\mathrm{g})$ & $A \%{ }^{15} \mathrm{~N}$ & \%NPU & mg NPU \\
\hline 0 a 3 & & & 0,545 & 1,76 & 1,43 \\
\hline 3 a 6 & & & 0,479 & 1,10 & 0,89 \\
\hline 6 a 9 & & & 0,494 & 1,25 & 1,01 \\
\hline 9 a 12 & & & 0,733 & 3,62 & 2,94 \\
\hline 12 a 15 & $860 \pm 130$ & 94,5 & 0,589 & 2,19 & 1,78 \\
\hline 15 a 18 & & & 0,505 & 1,36 & 1,10 \\
\hline 18 a 21 & & & 0,475 & 1,06 & 0,86 \\
\hline 21 a 24 & & & 0,493 & 1,24 & 1,01 \\
\hline 24 a 27 & & & 0,558 & 1,89 & 1,53 \\
\hline \multirow[t]{2}{*}{27 a 30} & & & 0,606 & 2,36 & 1,92 \\
\hline & & & & Total & $14,47 \mathrm{mg}$ \\
\hline
\end{tabular}

Os resultados das análises de uréia no efluente da coluna 6, após a aplicação do $2^{\circ}$ pulso, são mostrados na Tabela 15 . A recuperação calculada pelo volume e concentração de cada amostra foi de 1,62 mg, o que equivale a $8,1 \%$ do $2^{8}$ pulso, ou $4,05 \%$ do total ( 2 pulsos) aplicado nesta coluna. Na figura 9 são mostrados os pontos experimentais e as cur vas de passagem teóricas para esta mesma coluna.

As diferentes curvas são apresentadas para efeito comparativo. Note-se que neste coluna o problema é idêntico ao da coluna 5: é necessária uma grande alteração no tempo de pulso $t_{1}$, principalmente, pa- 
Tabela 15 -Recuperação de uréia no efluente da coluna 6. Solo de várzea.

\begin{tabular}{|c|c|c|c|}
\hline $\begin{array}{c}\text { Tempo } \\
(\mathrm{h})\end{array}$ & $\begin{array}{c}\mathrm{C} \\
(\mathrm{ppm})\end{array}$ & $\mathrm{C} / \mathrm{Co}$ & $\begin{array}{l}\mu g \text { uréia } \\
\text { (vol.xC) }\end{array}$ \\
\hline 86,49 & 1,2 & 0,012 & 9,7 \\
\hline 88,35 & 1,4 & 0,014 & 11,3 \\
\hline 90,21 & 1,7 & 0,017 & 13,7 \\
\hline 92,07 & 3,2 & 0,032 & 25,8 \\
\hline 93,93 & 4,5 & 0,045 & 36,2 \\
\hline 95,79 & 4,4 & 0,044 & 35,4 \\
\hline 97,65 & 6 & 0,060 & 48,3 \\
\hline 99,51 & 6 & 0,060 & 48,3 \\
\hline 101,37 & 10,2 & 0,102 & 82,1 \\
\hline 103,23 & 10,8 & 0,108 & 86,9 \\
\hline 105,09 & 10,8 & 0,108 & 86,9 \\
\hline 106,95 & 10,8 & 0,108 & 86,9 \\
\hline 108,81 & 10,8 & 0,108 & 86,9 \\
\hline 110,67 & 12 & 0,12 & 96,6 \\
\hline 112,53 & 16,6 & 0,166 & 133,6 \\
\hline 114,39 & 13 & 0,133 & 104,6 \\
\hline 116,25 & 11,9 & 0,119 & 95,8 \\
\hline 118,11 & 11,9 & 0,119 & 95,8 \\
\hline 119,97 & 10,7 & 0,107 & 86,1 \\
\hline 121,83 & 10,1 & 0,101 & 81,3 \\
\hline 123,69 & 10,8 & 0,108 & 86,9 \\
\hline 125,55 & 9,6 & 0,096 & 77,3 \\
\hline 127,41 & 6,3 & 0,063 & 50,7 \\
\hline 129,27 & 2,9 & 0,029 & 23,3 \\
\hline 131,13 & 2,4 & 0,024 & 19,3 \\
\hline 132,99 & 1,8 & 0,018 & 14,5 \\
\hline
\end{tabular}

$\mathrm{Co}_{\mathrm{O}}=100 \mathrm{ppm}$

Vazão $=4 \mathrm{~m} \ell / \mathrm{min}$

Pulso de $200 \mathrm{~m} \ell$

$t=0$ no início da infiltração do pulso 




Figura 9 - Pontos experimentais e curvas de passagem teóricas para o $2^{8}$ pulso de uréia na coluna 6 . Solo de vár zea. 
ra que se obtenha a curva que melhor se ajusta aos pontos experimentais; duas delas produzem resultados satisfatórios com valores diferentes de $t_{1}$ e $k$. Isto vem reforçar a hipótese de que estes parâmetros não refletem as características reais do solo, sendo somente valores aproximados.0 cálculo da quantidade de uréia recuperada no efluente pela área da curva de melhor ajuste, feita de maneira idéntica à coluna 5, resultou em 1,56 mg, bastante semelhante ao resultado apresentado na Tabela 15. Pelas características dos pontos experimentais da figura 9, e admitindo-se que o $1^{8}$ pulso se comportou de maneira idêntica, pode-se assegurar que o intervalo de tempo entre os dois pulsos foi suficiente para que não restasse uréia do $1^{8}$ pulso na coluna, ou seja, o que não foi transformado do $1^{8}$ pulso deve ter deixado a coluna completamente quando se iniciou o $2^{8}$ pulso. Infelizmente as amostras relativas ao efluente do $1^{8}$ pulso foram per didas. Porém, lembrando-se que o solo desta coluna é o mesmo que o da co luna 5, pode-se supor, para efeito comparativo, um comportamento semelhan te para o $1^{8}$ pulso da coluna 6. Tendo isto em mente, note-se então que a recuperação de uréia no efluente do $2^{8}$ pulso seria bem menor que no $1^{8}$, reforçando-se a hipótese já formulada de que neste solo existe variação temporal na atividade da urease.

Na Tabela 16 são apresentados os resultados das análises de $N$ total e recuperação de ${ }^{15} \mathrm{~N}$ do solo da coluna 6 ao término do experimento, e na Tabela 17 estão os resultados das análises de $\mathrm{NH}_{4}^{+}-\mathrm{N}$ no eflü ente desta coluna. Não foram feitas análises isotópicas para o $\mathrm{NH}_{4}^{+}-\mathrm{N}$.

A quantidade de nitrogénio recuperada no solo ao final do experimento foi de $24,32 \mathrm{mg}$ ou $60,8 \%$ do total aplicado ( 2 pulsos). Estes 
dados indicam que parte do $1^{8}$ pulso aplicado se encontra retido no solo ao final do experimento, provavelmente na forma de $\mathrm{NH}_{4}^{+}$.

0 total recuperado no efluente, na forma de $\mathrm{NH}_{4}^{+}-\mathrm{N}$, e cal culado pelo volume e concentração das amostras, foi de $8,24 \mathrm{mg}$, ou $20,6 \%$ do total aplicado (2 pulsos). Admitindo-se que todo o $\mathrm{NH}_{4}^{+}-\mathrm{N}$ no efluente seja proveniente somente da uréia aplicada, teríamos então uma recuperação geral de $34,18 \mathrm{mg}$ ou $85,45 \%$ do total aplicado. A diferença, ou se ja, 5,82 mg, é a quantidade que deixou a coluna na forma de uréia, resul tante da aplicação do $1^{8}$ pulso. Note-se que este número é bastante semeIhante ao obtido para a coluna 5 (Tabela 13).

Tabela 16 - Distribuição e recuperação de ${ }^{15} \mathrm{~N}$ no solo da conuna 6. Solo de várzea.

\begin{tabular}{|c|c|c|c|c|c|}
\hline $\begin{array}{c}\text { Camada } \\
(\mathrm{cm})\end{array}$ & $\begin{array}{c}N \text { total } \\
(\text { ppm })\end{array}$ & $\operatorname{MASSA}(\mathrm{g})$ & $A \%{ }^{15} \mathrm{~N}$ & ¿NPU & mg NPU \\
\hline 0 a 3 & & & 0,768 & 3,97 & 2,60 \\
\hline 3 a 6 & & & 0,946 & 5,74 & 3,77 \\
\hline 6 a 9 & & & 0,907 & 5,35 & 3,51 \\
\hline 9 a 12 & & & 0,962 & 5,90 & 3,87 \\
\hline 12 a 15 & $677 \pm 170$ & 97 & 0,951 & 5,79 & 3,80 \\
\hline 15 a 18 & & & 0,788 & 4,17 & 2,73 \\
\hline 18 a 21 & & & 0,641 & 2,71 & 1,78 \\
\hline 21 a 24 & & & 0,547 & 1,78 & 1,17 \\
\hline 24 a 27 & & & 0,520 & 1,51 & 0,99 \\
\hline \multirow[t]{2}{*}{27 a 30} & & & 0,384 & 0,16 & 0,10 \\
\hline & & & & \multicolumn{2}{|c|}{ Total $=24,32$} \\
\hline
\end{tabular}

Na coluna 7, montada com o mesmo solo que as colunas 5 e 6 , foi admitido uréia em regime de alimentação contínua, com um pulso inter- 
Tabela 17 - Recuperação de $\mathrm{NH}_{4}^{+}$no efluente da coluna 6. Solo de várzea.

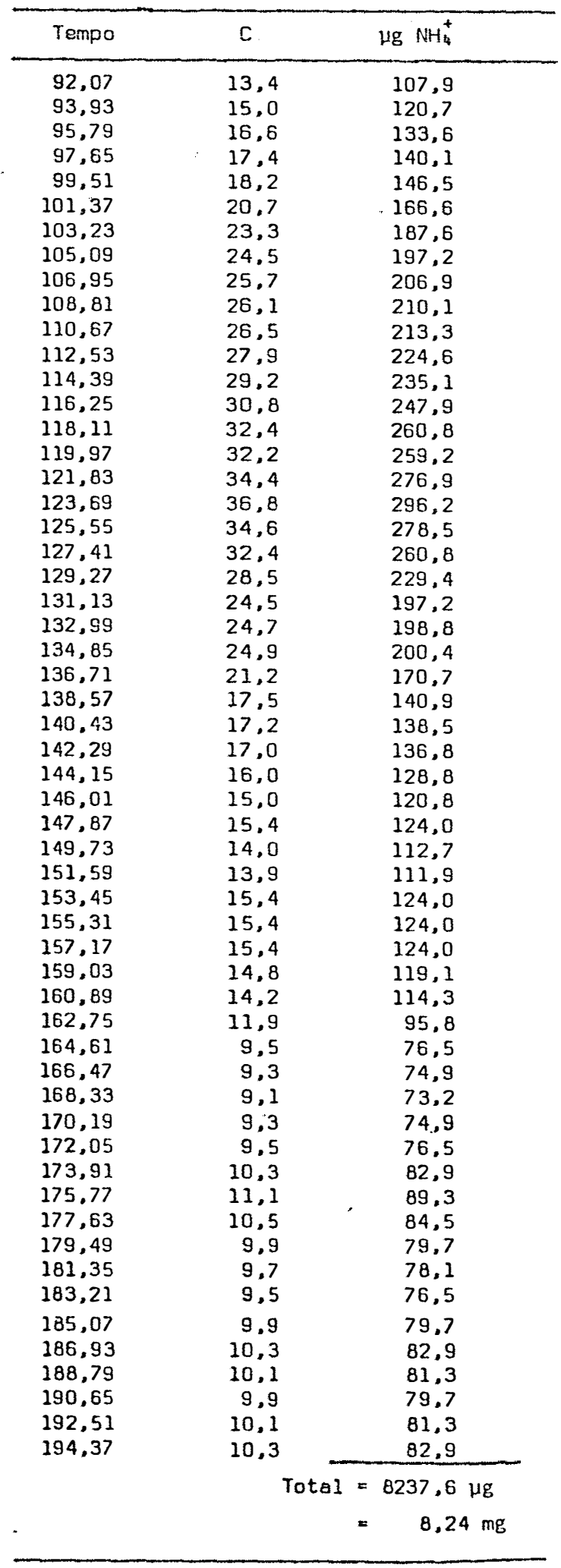


mediārio de uréia $-{ }^{15} \mathrm{~N}$. Na figura 10 são apresentados os pontos experimentais e a curva de passagem teórica. A introdução e tempo de duração do pulso de uréia $-{ }^{15} \mathrm{~N}$ é indicada na figura pelas duas setas verticais na curva de alimentação contínua. Pela análise dos dados fica evidente a existência de variação temporal da atividade da urease neste solo. Portanto, o modelo matemático aqui proposto é falho em descrever o deslocamento miscível de uréia neste solo. Seria conveniente a utilização do ín cloreto para se determinar a velocidade e dispersão reais neste solo. 0 valor do fator de transformação $K=0,003 \mathrm{~h}^{-1}$ utilizado na obtenção da curva de passagem teórica da figura 10 dão uma idéia da condição inicial da atividade da urease. No tempo de 733 horas, ou aproximadamente 30 dias, foram coletadas duas amostras a cada $5 \mathrm{~cm}$ no perfil da coluna, e as mesmas foram analisadas para determinação da concentração de uréia. Os resultados são apresentados na figura 11 , onde a curva sólida representa a distribuição teórica obtida utilizando-se os mesmos valores de $v$ e D da figura 10. Foi no entanto, utilizado um fator de transformação $K=0,042$ $\mathrm{h}^{-1}$, que é 14 vezes maior que o utilizado na obtenção da curva da figura 10. Praticamente $90 \%$ da uréia é transformada nos primeiros $10 \mathrm{~cm}$ da colu na.

Na Tabela 18 são apresentados os resultados obtidos na anä lise de $\mathrm{NH}_{4}^{+}$- trocável e $\mathrm{NH}_{4}^{+}-{ }^{15} \mathrm{~N}$ no solo, ao final do experimento, e na figura 12 se encontra a representação gráfica destes dados. Observa-se que a maior parte do $\mathrm{NH}_{4}^{+}-\mathrm{N}$ se encontra acumulado nos primeiros $15 \mathrm{~cm}$ da coluna, o mesmo acontecendo para o $\mathrm{NH}_{4}^{+}-{ }^{15} \mathrm{~N}$, indicando que a maior ativi dade da urease se localiza realmente nos primeiros $10 \mathrm{~cm}$ de solo. 0 to- 


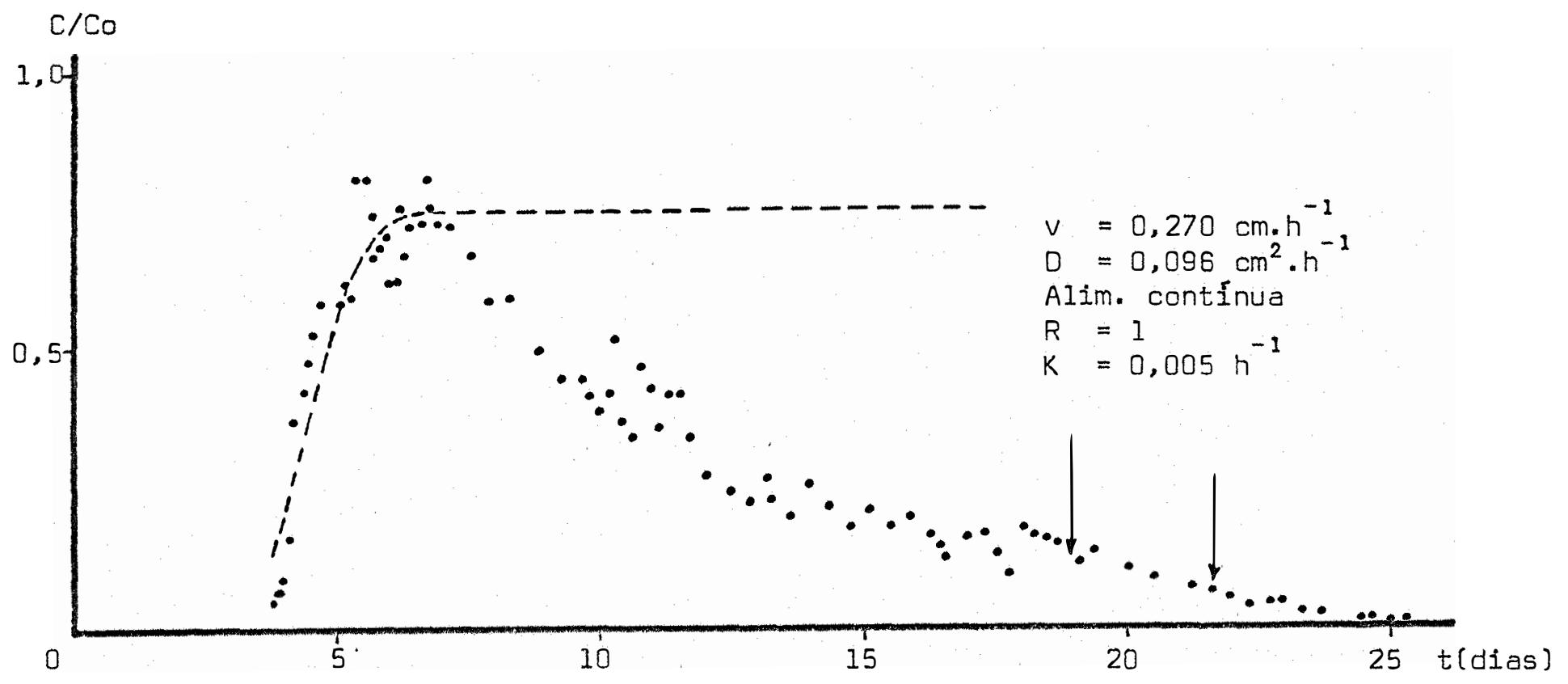

Figura 10 - Pontos experimentais e curva de passagem teórica para alimentação contínua de uréia na coluna 7. Solo de värzea. 


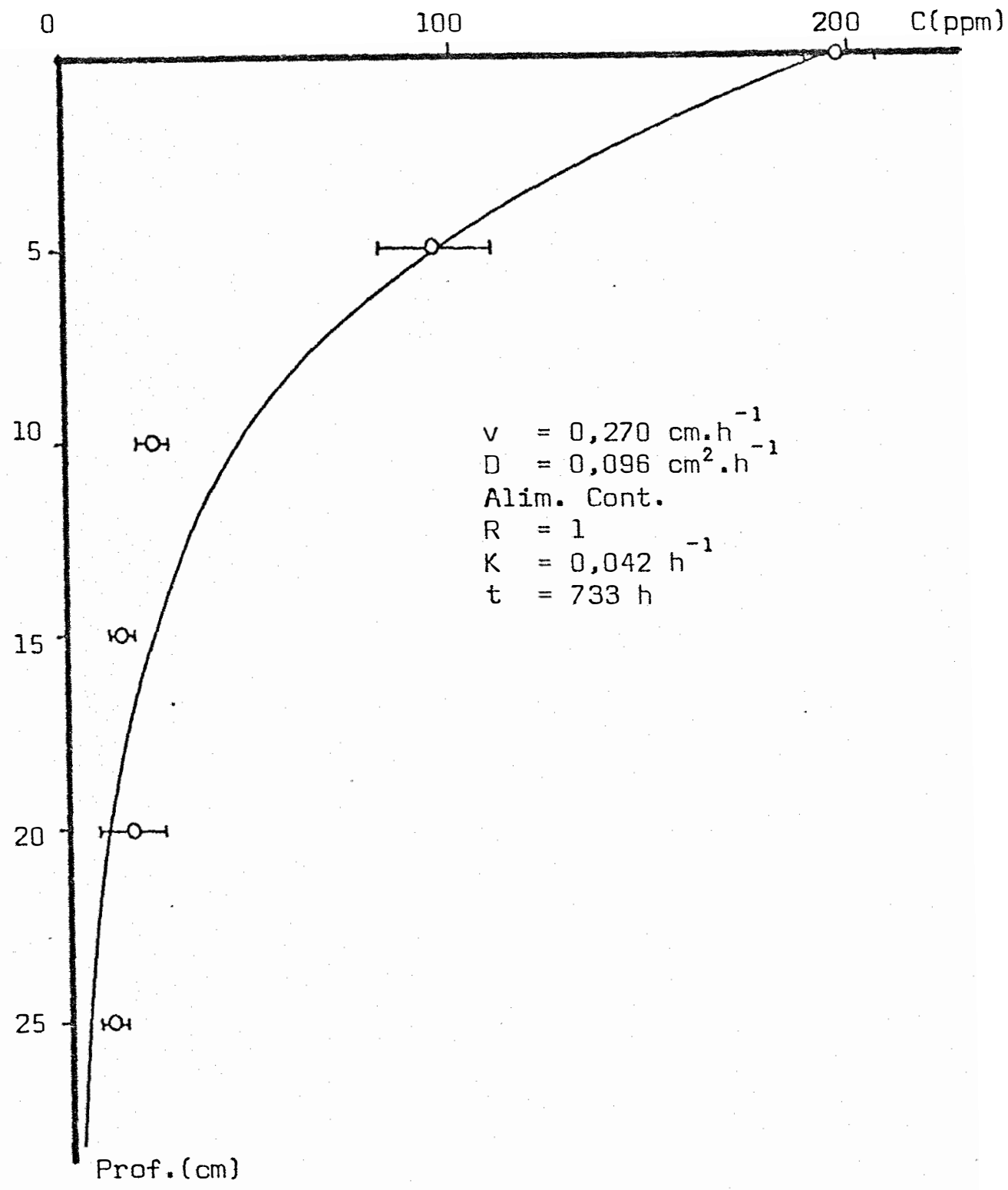

Figura 11 - Distribuições experimental e teórica de uréia ao longo da coluna 7. Solo de várzea. 


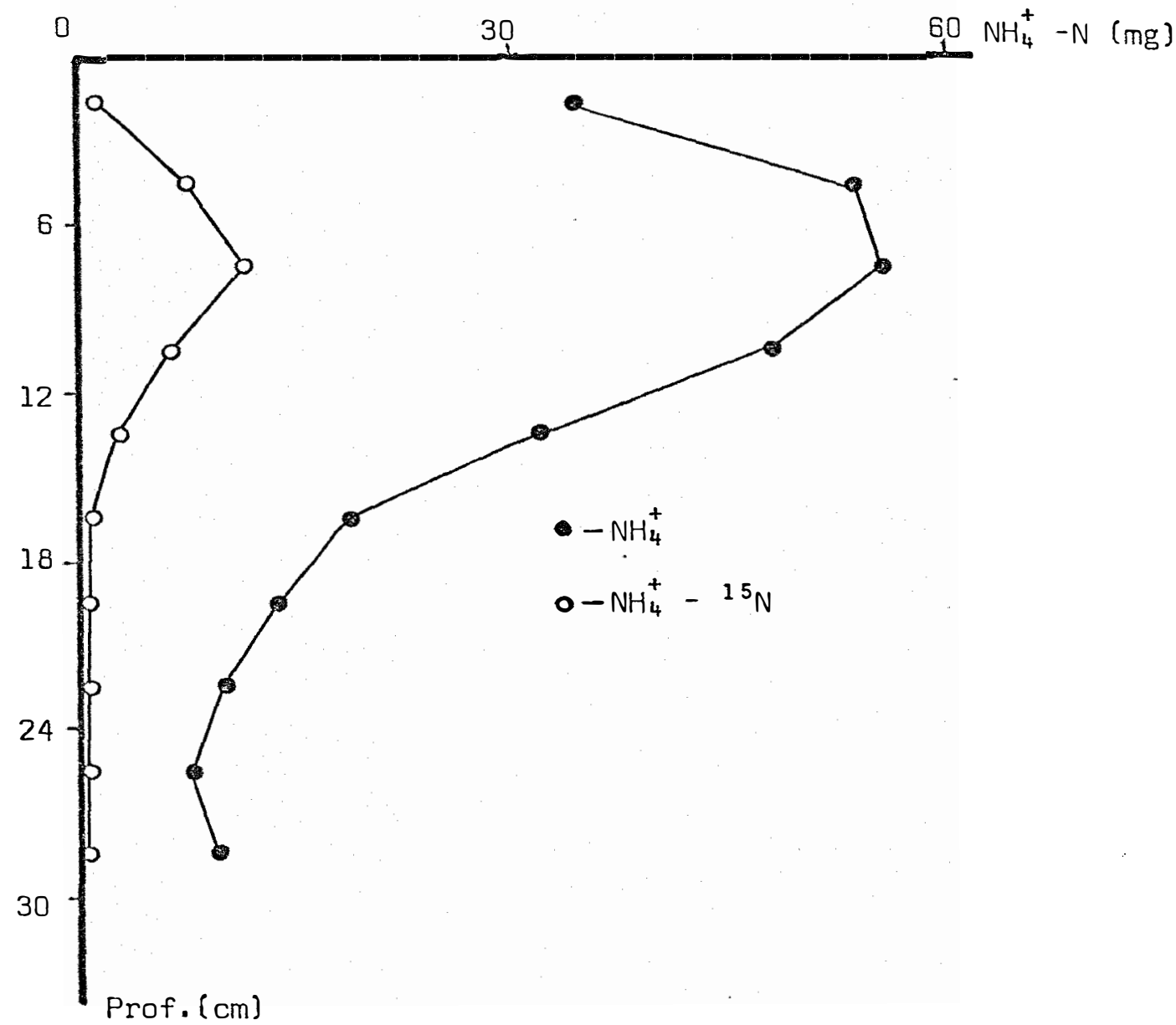

Figura 12 - Distribuição de $\mathrm{NH}_{4}^{+}-\mathrm{N}$ e $\mathrm{NH}_{4}^{+}-{ }^{15} \mathrm{~N}$ em função da profundidade para a coluna 7. Solo de värzea. 
Tabela 18 - Distribuição e recuperação de $\mathrm{NH}_{4}^{+}-{ }^{15} \mathrm{~N}$ (extração com KCl 2N) no solo da coluna 7. Solo de várzea.

\begin{tabular}{cccrc}
\hline $\begin{array}{c}\text { Camada } \\
(\mathrm{cm})\end{array}$ & $\mathrm{NH}_{4}^{+}(\mathrm{mg})$ & $A \%{ }^{15} \mathrm{~N}$ & $\% \mathrm{NPU}$ & $\mathrm{mg} \mathrm{NPU}$ \\
\hline 0 a 3 & 35,36 & 0,628 & 2,58 & 0,92 \\
3 a 6 & 53,55 & 1,751 & 13,76 & 7,35 \\
6 a 9 & 55,30 & 2,445 & 20,63 & 11,41 \\
9 a 12 & 48,0 & 1,698 & 13,21 & 7,30 \\
12 a 15 & 32,0 & 1,050 & 6,77 & 2,71 \\
15 a 18 & 19,50 & 0,739 & 3,68 & 0,72 \\
18 a 21 & 13,89 & 0,591 & 2,21 & 0,31 \\
21 a 24 & 10,91 & 0,597 & 2,27 & 0,25 \\
24 a 27 & 8,30 & 0,688 & 3,18 & 0,26 \\
27 a 30 & 10,44 & 0,675 & 3,05 & 0,32 \\
\hline
\end{tabular}

Tabela 19 - Distribuição e recuperação de $N$ orgàníco $e^{15} \mathrm{~N}$ - or gânico no solo da coluna 7. Digestão de Kjeldhal a pós extração com KCl $2 \mathrm{~N}$. Solo de várzea.




tal de nitrogénio marcado recuperado foi de $31,55 \mathrm{mg}$, equivalente a $78,9 \%$ do total aplicado. A distribuição de $\mathrm{NH}_{4}^{+}$- trocável ao longo da coluna é bastante semelhante ao que foi encontrado por WAGENET et alii (1977).

Na Tabela 19 são apresentados os resultados da análise de $N$ orgánico e ${ }^{15} \mathrm{~N}$ - orgánico do solo ao final do experimento. É pequena a quantidade que permanece em forma não trocável no solo, e está em " sua maior parte também concentrada nos $15 \mathrm{~cm}$ iniciais da coluna. É provável que tal nitrogênio esteja retido na forma orgânica, compondo a biomassa do solo. O total recuperado desta maneira foi de $1,81 \mathrm{mg}$, equivalente a $4,5 \%$ do total aplicado.

Somente $0,47 \mathrm{mg}$, ou seja, 1,2\% do total aplicado, foi recu perado como $\mathrm{NH}_{4}^{+}-{ }^{15} \mathrm{~N}$ no efluente desta coluna, conforme pode ser visto na Tabela 20.

Na Tabela 21 é apresentado um resumo dos principais resultados obtidos com as 7 colunas. Os dados de velocidade e dispersão para as quatro primeiras colunas são semelhantes aos que foram obtidos por NASCIMENTO $F^{8}$ (1978) e os das três últimas colunas são semelhantes aos ob tidos por WAGENET et alii (1977). Com exceção da coluna 3, os dados seguem a tendência de aumento da difusão com o aumento da velocidade (NASCI MENTO $\mathrm{F}^{\circ}, 1978$; BIGGAR e NIELSEN 1976a).

Pode ser observado na Tabela 2 a extrema semelhança nas cạ racterísticas físicas das colunas 1 e 2 , porém os dados da Tabela 21 reve lam uma grande diferença nas características de transporte de uréia nestas colunas especialmente com relação à velocidade da solução do solo. A 
única explicação possível para esta diferença está no fato de terem sido utilizadas soluções deslocadoras diferentes para as duas colunas: água destilada para a coluna 1 e $\mathrm{CaSO}_{4}$ 0,0IN para a coluna 2. Note-se, pela Tabela 1, que este solo é bastante pobre em $\mathrm{Ca}^{2^{+}}$no complexo de troca,sen do este último provavelmente dominado pelos íons $\mathrm{H}^{+}$. A utilização de uma solução deslocadora de $\mathrm{CaSO}_{4}$ seguramente irá alterar as condições do complexo de troca, acarretando então diferença nas características de trans porte. Reforça esta hipótese o fato de não ter havido diferenças tão mar cantes entre as colunas 2 e 3 . A comprovação definitiva desta hipótese

Tabela 20 - Recuperação de $\mathrm{NH}_{4}^{+}-{ }^{15} \mathrm{~N}$ no efluente da coluna 7. Solo de várzea.

\begin{tabular}{lccccc}
\hline Amostra & $C(p p m)$ & $\begin{array}{c}\text { Volume } \\
(\mathrm{ml})\end{array}$ & $\mathrm{A} \%^{15} \mathrm{~N}$ & $\% \mathrm{NPU}$ & $\mathrm{mg} \mathrm{NPU}$ \\
\hline 207 a 226 & 170,0 & 0,369 & - & - \\
227 a 254 & 238,0 & 0,695 & 3,20 & 0,13 \\
255 a 266 & & 102,0 & 1,131 & 7,58 & 0,13 \\
267 a 278 & $16,6 \pm 2,5$ & 102,0 & 0,832 & 4,61 & 0,08 \\
279 a 286 & & 75,0 & 0,695 & 3,25 & 0,04 \\
287 a 296 & 85,0 & 0,667 & 2,97 & 0,04 \\
297 a 308 & 102,0 & 0,690 & 3,20 & 0,05 \\
& & & & Total $=$ & $0,47 \mathrm{mg}$ \\
& & & & & \\
\hline
\end{tabular}

necessita, no entanto, de maiores esforços neste sentido, no futuro.

Outro ponto a que se deve chamar a atenção é com relação aos fatores de transformação. O fato de se encontrar o mesmo valor para 
Tabela 21 - Resumo dos principals resultados dos diferentes experimentos.

\begin{tabular}{|c|c|c|c|c|c|c|c|c|c|c|}
\hline Coluna & Solo & $v$ & D & $R$ & $U$ & $\begin{array}{l}\text { Uré1a-N ef luente } \\
(\%) \text { teórico }\end{array}$ & $\begin{array}{c}\mathrm{NH}_{4}^{+}-\mathrm{N} \text { ef luente } \\
\%\end{array}$ & $\begin{array}{c}\mathrm{NH}_{4}^{+} \text {trocável } \\
\%\end{array}$ & N Solo & Total \\
\hline 1 & $A$ & $1,73 \mathrm{~cm} / \mathrm{min}$ & $0,88 \mathrm{~cm}^{2} / \mathrm{mln}$ & 1,32 & $0,006 / \mathrm{min}$ & 87,4 & - & - & - & \\
\hline 3 & $A$ & $0,768 \mathrm{~cm} / \mathrm{min}$ & $0.814^{\mathrm{a}} \mathrm{cm}^{2} / \mathrm{min}$ & $1,13^{\mathrm{a}}$ & $0,003 / \mathrm{min}$ & 87,7 & 4,2 & 2,3 & 0.6 & 94,8 \\
\hline 4 & $B$ & $0.198 \mathrm{~cm} / \mathrm{m} 1 \mathrm{n}$ & $0,291 \mathrm{~cm}^{2} / \mathrm{m} 1 \mathrm{n}$ & $1,12^{a}$ & $0,0009 / \mathrm{min}$ & 85,8 & 11.2 & 0,1 & 0,6 & 97.7 \\
\hline 5 & $c$ & $0.216 \mathrm{~cm} / \mathrm{h}$ & $0,07 \mathrm{~cm}^{2} / \mathrm{h}$ & - & $0,003 / \mathrm{h}$ & 34,5 & - & - & $72,30^{c}$ & 106,8 \\
\hline 6 & c & $0.267 \mathrm{~cm} / \mathrm{h}$ & $0.078 \mathrm{~cm}^{2} / \mathrm{h}$ & - & $0,01 / \mathrm{h}$ & $3,9+17,2^{b}$ & 20,6 & - & $60,80^{c}$ & 102.5 \\
\hline 7 & $c$ & $0.27 \mathrm{~cm} / \mathrm{h}$ & $0.096 \mathrm{~cm}^{2} / \mathrm{h}$ & - & $0,003-0,042 / \mathrm{r}$ & $/ h$ & 1,2 & 78,9 & 4,5 & 84,6 \\
\hline
\end{tabular}

a - valores calculados

b - Cólculado com a quantidade de uréia no efluente da coluna 5

c - Incluem $\mathrm{NH}_{4}^{+}$- torcável. 
o fator de transformação em duas colunas não significa necessariamente que a quantidade transformada seja a mesma. Deve ser lembrado que a transfor mação neste caso, estando ligada a um processo dinâmico de transporte, es tará também ligada à velocidade deste processo. Veja-se, por exemplo, as colunas 1 e 2, onde o fator de transformação tem o mesmo valor, porém a quantidade de uréia transformada é maior na coluna 2, que tem menor velocidade. Note-se, também, que para a coluna 3 o fator de transformação é bem menor que o da coluna 1, muito embora as quantidades de uréia transformada sejam praticamente idênticas; a velocidade na coluna 3, porém, tam bém é bem menor que a da coluna 1 . Este mesmo fato se repete para a colu na 4.

WAGENET et alii (1977) utilizam-se do mesmo fator de trans formação ao descrever o deslocamento miscível de uréia em diferentes colu nas do mesmo solo; porém, em pelo menos duas das colunas utilizadas para a determinação do fator, é evidente que naquela em que a velocidade do fluxo era menor a quantidade de uréia transformada foi maior. Isto talvez justifique o ajuste imperfeito de algumas de suas curvas de passagem.

Para os solos Podzólicos Vermelho-Amarelo (A) e Latossolo Amarelo (B) o modelo matemático utilizado ajusta-se perfeitamente aos dados experimentais, porém o mesmo não pode ser dito com relação ao solo de várzea (C), onde foram necessárias alterações grosseiras, principalmente no tempo de pulso, para que se obtivesse uma curva de passagem teórica ra zoavelmente ajustada aos dados experimentais. Os valores de $v$ e $D$ obtidos para as colunas deste solo são somente aproximações dos valores reais. Como já foi dito anteriormente, a utilização do ín $C \ell^{-}$seria o ca- 
minho ideal para a determinação dos valores reais de $v$ e $D$, neste caso.

A principal razão pela qual o modelo matemático não se ajusta aos pontos experimentais para o solo de várzea reside no fato de que a atividade da urease varia com o tempo. ARDAKANI et alii (1975) tam bém observaram a existēncia de variação temporal da atividade da urease trabalhando com um solo areno-barrento. Apresentam valores que variaram de $0,07 \mathrm{~h}^{-1}$ após 4 dias de alimentação contínua de uréia; no $30^{8}$ dia toda a uréia era transformada nos primeiros $10 \mathrm{~cm}$ da coluna. 0 mesmo acontece no caso deste trabalho, conforme pode ser visto na figura 11.

A atividade da urease em solos pode ser atribuida à urease do humus (BURNS et alii, 1972) e ao crescimento de bactérias ureolíticas (PAULSON e KURTZ, 1969). No caso de um solo de várzea é de se esperar uma maior atividade da urease, pois sua matéria orgânica encontra-se provavelmente em estado adiantado de humificação. Porém é mais provável que o aumento da atividade com o tempo seja devido ao crescimento bacteriano, e os dados da Tabela 19 indicam este fato.

Os valores de R na Tabela 21, e a não concordância temporal entre as curvas de passagem de $c l^{-}$e uréia nas figuras 2 e 3 indicam que a retenção de uréia nos solos Podzólico Vermelho-Amarelo e Latossolo Amarelo, é bastante pequena. Os valores de $R$ variaram de 1,12 a 1,32, e são bastante semelhantes ao valor de 1,31 encontrado por WAGENET et alii (1977) para um solo argilo-barrento da Califórnia. De qualquer maneira os valores encontrados são bastante pequenos quando comparados com valores de $\mathrm{R}$ igual a 12,9 para $\mathrm{NH}_{4}^{+}$(WAGENET et alii, 1977). 


\section{CONCLUSOES}

Tendo em vista os resultados apresentados pode-se chegar às seguintes conclusões:

1. O modelo matemático utilizado ajusta-se perfeitamente aos dados experimentais para os solos Podzólico VermelhoAmarelo e Latossolo Amarelo.

2. O modelo matemático é falho em descrever o deslocamento miscível da uréia no solo de várzea. A principal razão pa. ra isto reside no aumento da atividade da urease com o tem po, neste solo.

3. E sempre importante que se utilize, pelo menos uma vez, - Ion $\mathrm{Cl}^{-}$para a determinação da dispersão em um solo,prin cipalmente em solos com características semelhantes ao solo de värzea. E também, igualmente importante, que se tenha idéia da dināmica da população microbiana do solo. Tra balhos futuros deverão levar isto em consideração. 
4. A retenção de uréia nos solos Podzólico Vermelho-Amarelo foi bastante pequena e os valores encontrados se comparam àqueles existentes na literatura. A fraca retenção da uréia nestes casos, não é suficiente para impedir sua pronta lixiviação no solo saturado.

5. E preciso que se tenha um cuidado especial na interpretação dos fatores de transformação. Sendo a transformação, neste caso, parte de um processo dināmico, ela está intima mente ligada à velocidade deste. Assim, solos para os quais se obtiveram fatores de transformação iguałs, não tị veram necessariamente a mesma quantidade de uréia transfor mada; ela dependeu da velocidade do deslocamento.

6. Para os casos em que foi utilizada uréia marcada a recu peração variou de 85 a 107\%. Para os solos Podzólico Vermelho-Amarelo e Latossolo Amarelo, a maior parte (81-87\%) da uréia aplicada foi recuperada no efluente da coluna na forma de uréia. Para o solo de várzea a maior parte (6078\%) foi recuperada no solo, após o experimento, na forma de $\mathrm{NH}_{4}^{+}$- trocável. 


\section{BIBLIOGRAFIA}

ARDAKANI, M.S.; M.G. VOLZ e A.D. MCLAREN, 1975. Consecutive steady state reactions of urea, ammonium and nitrite nitrogen in soil. Can. J. Soil. Sci. 55: $83-91$.

BERAN, M.J., 1955. Dispersion of soluble matter in slowly moving fluids. Tese de PhD (não publicada). Harvard Univ. Cambridge, Mass, USA.

BIGGAR, J.W. e D.R. NIELSEN, 1962. Miscible displacement. II. Behavior of tracers. Soil Sci. Soc. Amer. Proc. Madison 26:125-128.

BIGGAR, J.W. e D.R. NIELSEN, 1964. Chloride-36 diffusion during stable and unstable flow through glass beads. Soil Sci. Soc. Amer. Proc. Madison 28:591-595.

BIGGAR, J.W. e D.R. NIELSEN, 1967. Miscible displacement and leaching phenomenon In: HAGAN, R.M., H.R. HAISE \& T.W. EDMINSTER (eds). Irrigation of Agricultural Lands. Madison, ASA, serie Agronomy no. 11, 
Cap. 14, p. 254-274.

BIGGAR, J.W. e D.R. NIELSEN, 1976a. SpatiaI variability of the leaching characteristics of a field soil. Water Res. Res. Washington 12:78-74.

BIGGAR, J.W. e D.R. NIELSEN, 1976b. Mechanism of chemical movement in soils. Israel, Relatório apresentado na reunião da International Soil Science Society 29p. (mimeografado).

BOAST, C.W., 1973. Modeling the movement of chemicals in soils by water. Soil Sci. Baltimore 115:224-230.

BREMNER, J.M., 1965a. Inorganic forms of nitrogen. In: C.A. BLACK, D.D. EVANS, J.L. WHITE, L.E. ENSMINGER e F.E. CLARK (eds) Methods of Soil Analysis. American Society of Agronomy no. 9, Cap. 84, p. 1179-1237.

BREMNER, J.M., 1965b. Total nitrogen. In: C.A. BLAC, 0.0. EVANS, J.L. WHITE, L.E. ENSMINGER e F.E. CLARCK (eds) Methods of Soil Analysis. American Society of Agronomy no. 9, Cap. 83, p. 1149-1178.

BREMNER, H., 1962. The diffusion model of longitudinal mixing in beads of finite lenghts. Numerical values Chem. Engng Sci. Londres 17: 229-243.

BROWN, B.D. e O.E. ROLSTON, 1980. Transport and transformation of methyl bromide in soils. Soil Sci. 130:68-78. 
BURNS, R.G., A.H. PUKITE e A.D. MCLAREN, 1972. Concerning the colation and persistence of soil urease. Soil Sci. Soc. Amer. Proc. 36:308-311.

CAMARGO, O.A.; J.W. BIGGAR e D.R. NIELSEN, 1979. Efeito do cálcio ou do potássio na adsorção e movimento do fúsforo em um alfisol. Rev. bras. Ci. Solo Campinas $\underline{3}:$ 8-13.

CASSEL, D.K., 1971. Water and solute movement in svea loam for two water management regimes. Soil Sci. Soc. Amer. Proc. Madison 35: 859-866

CASSEL, D.K.; T.H. KRUEGER, F.W. SHROES e E.B. NORUM, 1974. Solute movement through disturbed and undisturbed soil cores. Soil Sci. Soc. Amer. Proc. Madison 38: 36-40.

CASSEL, D.K.; M.Th. van GENUTCHEN e WIERENGA, 1975. Prediction of anion movement in disturbed and undisturbed soils. Soil Sci. Soc. Amer. Proc. Madison 39:1015-1019.

CASTRO, C.L. e D.E. ROLSTON, 1977. Organic phosphate transport and hidrolisis in soil: theoretical and experimental evaluation. Soil Sci. Soc. Amer. J. Madison 41:1085-1092.

CHO, C.M., 1971. Convective transport of ammonium with nitrification in soils. Can J. Soil Sci. Otawa 51:339-350. 
COATS, K.H. e B.D. SMITH, 1964. Dead-end pore volume and dispersion in porous media. Soc. Pet. Eng. J. 4:73-84.

COREY, J.C.; D.R. NIELSEN e J.W. BIGGAR, 1963. Miscible displacement in saturated and unsaturated sandstone. Soil Sci. Soc. Amer. Proc. Madison 31: 497-503.

COREY, J.C.; D.R. NIELSEN e D. KIRKHAM, 1967. Miscible displacement of nitrate throughi soil columns. Soil Sci. Soc. Amer. Proc. Madison 31: 497-503.

DANCKWERTS, P.V., 1953. Continuous flow systems: distribution of residence times. Chem. Eng. Sci. 2:1-13.

DAVIDSON, J.M.; J.M. MANSELL e D.R. BAKER, 1972. Herbicide distributions within a soil profile and their dependence upon adsorption. Soil Crop. Sci. Soc. Florida, Florida $32: 36-41$.

DAVIDSON, J.M.; L.T. OU E P.S.C. RAO, 1976. Behaviour of high pesticide concentration in soil water systems. Tucson, Proc. of Hazandous Waste Research Sump., U.S.E.P.A. and U. of Arizona 7p.

DAY, P.R. e W.M. FORSYTHE, 1957. Hidrodinamic dispersion of solutes in the soil moisture stream. Soil Sci. Soc. Amer. Proc. Madison 21:477480. 
DOUGLAS, L.A. e J.M. BREMNER, 1970. Colorimetric determination of microgram quantities of urea. Anal. Letters. 3:79-87.

FRISSEL, M.J. e P. POELSTRA, 1967. Chromatographic transport through soils. I. Theoretical evaluations. Plant \& Soil Haia 26:285-302.

HASHIMOTO, I.; K.B. DESHPANDE e H.C. THOMAS, 1964. Peclet numbers and retardation factors for ions exchange columns. Ind. Engng. Chem. (Fundamentals). Washington 3:213-218.

HOFFMAN, D.L. e D.E. ROLSTON, 1980. Transport of organic phosphate in soil as affected by soil type. Soil Sci. Soc. Amer. J. Madison 44: $46-52$.

KIRDA, C.; D.R. NIELSEN E J.W. BIGGAR, 1973. Simultaneous transport of chloride and water during infiltration. Soil Sci. Soc. Amer. Proc. Madison $37: 339-345$.

KIRKHAM, D. e W.L. POWERS, 1972. Miscible displacement. In: Advanced. Soil Physics New York. John Wi ley cap. 8, p. 379-427.

MCLAREN, A.D., 1970. Temporal and vectorial reactions of nitrogen in soil: a review. Can. J. So1l Sci. Otawa 50:97-109. 
MISRA, C.; D.R. NIELSEN e J.W. BIGGAR, 1974a. Nitrogen transformations in soil during leaching. I. Theoretical considerations. Soil Sci. Soc. Amer. Proc. Madison 38:289-293.

MISRA, C.; D.R. NIELSEN e J.W. BIGGAR, 1974b. Nitrogen transformations in soil during leaching. II. Steady-state nitrification and nitrate reduction. Soil Sci. Soc. Amer. Proc. Madison 38:294-299.

MISRA, C.; D.R. NIELSEN e J.W. BIGGAR, 1974c. Nitrogen transformations during continuous leaching. III. Nitrate reduction in soil columns. Soil Sci. Soc. Amer. Proc. Madison 38:300-304.

MISRA, C. e B.K. MISHRA, 1977. Miscible displacement of nitrat and chlorid under field conditions. Soil Sci. Soc. Amer. J. Madison 4l: 496-499.

NASCIMENTO Fi, V.F.do, 1978. Variabilidade espacial do deslocamento miscível do ín cloreto em solo saturado. Tese de Doutoramento. Piracicaba, ESALQ/USP, 142p.

NIELSEN, D.R. e J.W. BIGGAR, 1961. Miscible displacement. I. Experimental Information. Soil Sci. Soc. Amer. Proc. Madison 25: 1-5.

NIELSEN, D.R. e J.W. BIGGAR, 1962a. Miscible displacement. III. Theoretical considerations. Soil Sci. Soc. Amer. Proc. Madison 25: $1-5$. 
NIELSEN, D.R. e J.W. BIGGAR, 1962b. Some theoretical considerations of miscible displacement. In: ___ Investigation of Energy and Mass. Transfer near the Ground. Including Influences of the Soil - PlantAtmosphere System. Cap. XIV p. 165-183.

NIELSEN, D.R. e J.W. BIGGAR, 1963. Miscible displacement. IV. Mixing in glass beads. Soil. Sci. Soc. Amer. Proc. Madison 27: 10-13.

NIELSEN, D.R.; R.D. JACKSON; R.W. CARY e D.D. EVANS, 1972. Soil water. Madison Soc. of Agronomy, 175p.

PAULSON, K.N. e L.T. KURTZ, 1969. Locus of urease activity in soils. Soil Sci. Soc. Amer. Proc. 33:897-901.

PORTER, L.K.; W.D. KEMPER; R.D. JACKSDN e B.A. STEWART, 1960. Chloride diffusion in soils as influenced by moisture content. Soil Sci. Soc. Amer. Proc. Madison 24:460-463.

REICHARDT, K., 1975. A solução do solo. In: Processos de transferência. no sistema solo-planta-atmosfera. Piracicaba, CENA. Fundação Cargill Cap. 8, p. 146-175.

ROLSTON, D.E. e R.D. GLAUZ, 1980. A simulation model for transport and transformation of methyl bromide gas in soils. Soil Sci. Soc. Amer. J. $\{$ in press $\}$. 
RUZICKA, J.; J.W.B. STEWART e E.A.G. ZAGATTO, 1976. Flow injection analysis. Part 4. Stream sample splitting and its application to the continuous spectrophotometric determination of chloride in blackish waters. Anal. Chim. Acta. Ansterdam 81:387-396.

SELIM, H.M.; P. KANCHANASUT; R.S. MANSELL; L.W. ZELASNY E J.M. DAVIDSON, 1974. Phosphorus and chloride movement in a spodosol. Soil Crop. Sci. Soc. Florida. Florida 34:18-23.

SELIM, H.M.; R.S. MANSELL e A. ELZEFTAWY, 1976a. Distributions of 2,4-D and water in soil during infiltration and redistribution. Soil Sci. Baltimore 121:176-183.

SELIM, H.M.; R.S. MANSELL e L.W. ZELAZNY, 1976b. Modeling reactions and transport of potassium in soils. Soil Sci. Baltimore 122:77-84.

SELIM, H.M.; J.M. DAVIDSON e R.S. MANSELL, 1976c. Evaluation of a twosete adsorption-desorption model for describing transport in soil. Summer Computer Simulation Conf., 12-14 July, Washington p. 444-448.

SELIM, H.M.; J.M. DAVIDSON E P.S.C. RAO, 1977. Transport of reactive solutes through multilayered soils. Soil Sci. Soc. Amer. J. Madison 41: 3-10. 
SIDLE, R.C.; L.T. KARDDOS e M. Th. van GENUTCHEN, 1977. Heavy metals transport model in a sludge-treated soil. J. Environ. Qual. Madison 6: $438-443$

STARR, J.L.; F.E. BROADBENT e D.R. NIELSEN, 1974. Nitrogen transformations during continuous leaching. Soil Sci. Soc. Amer. Proc. Madison 38: 283-289.

TAYLOR, G.I., 1953. Oispersion of soluble matter in solvent flowing slowly through a tube. Proc. Roy Soc. London 219A: 186-203.

TRIVELIN, P.C.D. ; E. SALATI e E. MATSUI, 1973. Preparo de amostras para análise de ${ }^{15} \mathrm{~N}$ por espectrometria de massa. CENA-USP, Piracicaba, BT-002, 4lp.

van GENUTCHEN, M.Th.; J.M. DAVIDSON e P.J. WIERENGA, 1974. An evaluation of kinetic and equilibrium equations for the prediction of pesticide movement through porous media. Soil Sci. Soc. Amer. Proc. Madison 38: 29-35.

van GENUTCHEN, M.Th. e P.J. WIERENGA, 1976. Mass transfer studies in sorbing porous media. I. Analytical solutions. Soil Sci. Soc. Amer. J. Madison 40:473-480. 
VAN GENUTCHEN, M. Th e P.J. WIERENGA, 1977. Mass transfer studies in porous media. II. Experimental evaluation with tritium. Soil Sci. Soc. Amer. J. Madison 41:272-278.

VAN RAIJ, B. e M.A.T. ZULLO, 1977. Métodos de análise de solos. Circular $n^{8}$ 63. Seção de Fertilidade do Solo-IAC, Campinas.

WAGENET, R.J.; J.W. BIGGAR e D.R. NIELSEN, 1976. Analytical solutions of miscible displacement equations describing the sequential microbiological transformations of urea, ammonium and nitrate. Water Science e Engineering Papers 6001. Un. of California, Davis, 53p. (mimiografado).

WAGENET, R.J.; J.W. BIGGAR e D.R. NIELSEN, 1977. Tracing the transformations of urea fertilizer during leaching. Soil Sci. Soc. Amer. J. Madison 41:896-902. 
APENDICE

Programa utilizado para cálculo das curvas de passagem teoo ricas utilizando um computador COMMODORE-PET.

0 programa foi desenvolvido com base na equação (57), que para simplicidade de processamento pode ser escrita como:

$$
\begin{aligned}
& \frac{C}{C o}=\frac{1}{2}\left[W \operatorname{erfc} A+W_{1} \operatorname{erfc} B-W \text { erfc } C-W_{1} \text { erfc } D\right] \\
& \text { sendo: } \\
& W=\exp \frac{x}{2 D}\left(v-\sqrt{v^{2}+4 D K}\right) \\
& W_{1}=\exp \frac{x}{2 D}\left(v+\sqrt{v^{2}+4 D K}\right) \\
& A=\operatorname{erfc}\left(\frac{\left.x-t \sqrt{v^{2}+4 D K}\right)}{\sqrt{4 D t}}\right. \\
& B=\operatorname{erfc}\left(\frac{\left.x+t \sqrt{v^{2}+4 D K}\right)}{\sqrt{4 D t}}\right. \\
& C=\operatorname{erfc}\left(\frac{x-\left(t-t_{1}\right) \sqrt{v^{2}+4 D K}}{\left.\sqrt{4 D\left(t-t_{1}\right.}\right)}\right)
\end{aligned}
$$




$$
D=\operatorname{erfc}\left|\frac{x+\left(-t_{1}\right) \sqrt{ } v^{2}+4 D K}{\sqrt{4} D\left(t-t_{1}\right)}\right|
$$

As funções de erro complementar foram calculadas de acordo com as equações fornecidas por NASCIMENTO Fi (1978).

Dados os valores de $v, D, t_{1}, R, K$ e $\times$ o programa calcula valores para concentração relativa em função do tempo de amostragem, comparando-os com os dados experimentais. Os valores para os quais se obtenha a menor soma de quadrado de desvios, são os que melhor descrevem os dados experimentais.

A seguir é apresentada uma listagem do programa com um exemplo de saída de dados. D computador utilizado trabalha com a linguagem BASIC de programação. Nos comandos 20 a 80 se encontram as opções de entrada de dados e definições das condições experimentais. Os comandos 154 a 340 efetuam os cálculos propriamente ditos e os comandos 365 a 485 oferecem possibilidade de mudança de um ou mais parámetros experimentais. Nos comandos 1010 a 1519 se situam os cálculos da função de erro complementar.

Como escrito, o programa admite a entrada de no máximo, 50 dados experimentais. Todavia este número poderá ser facilmente modificado através do comando 5 . 


\section{Listagem do Programa utilizado no cálculo de curvas de passa- gem teóricas.}

FEAI'T'.






\section{Coṇtinuação}

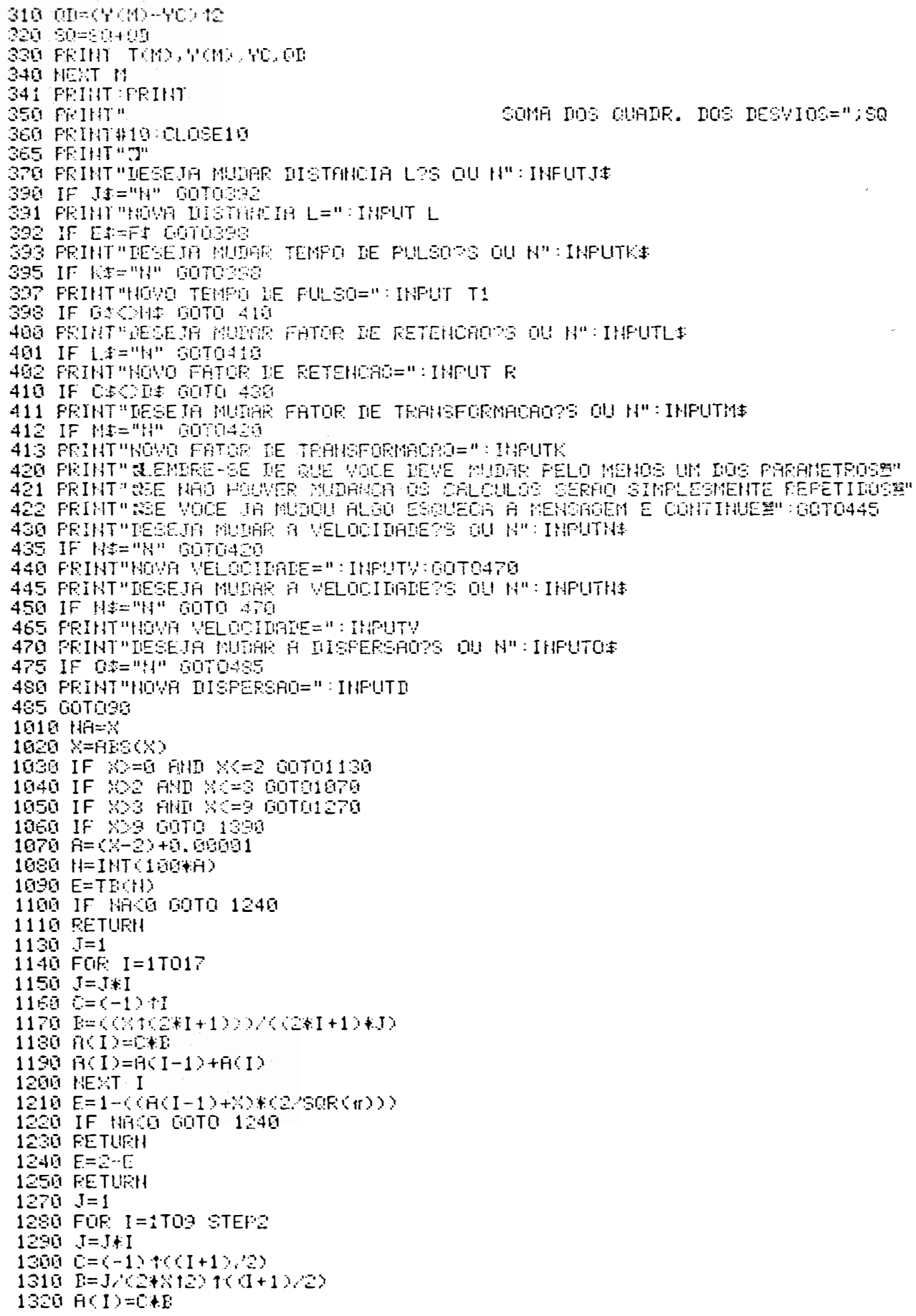




\section{Continuação}

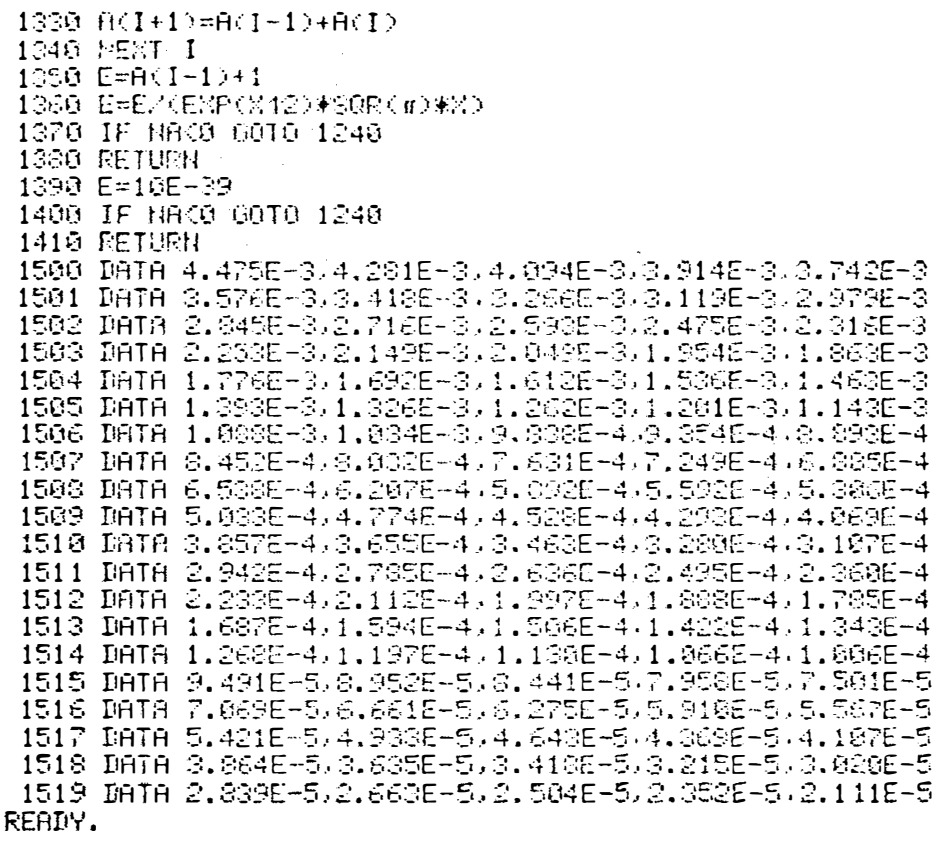


Saída de dados. Exemplo de uma das curvas obtidas para a coluna 2.

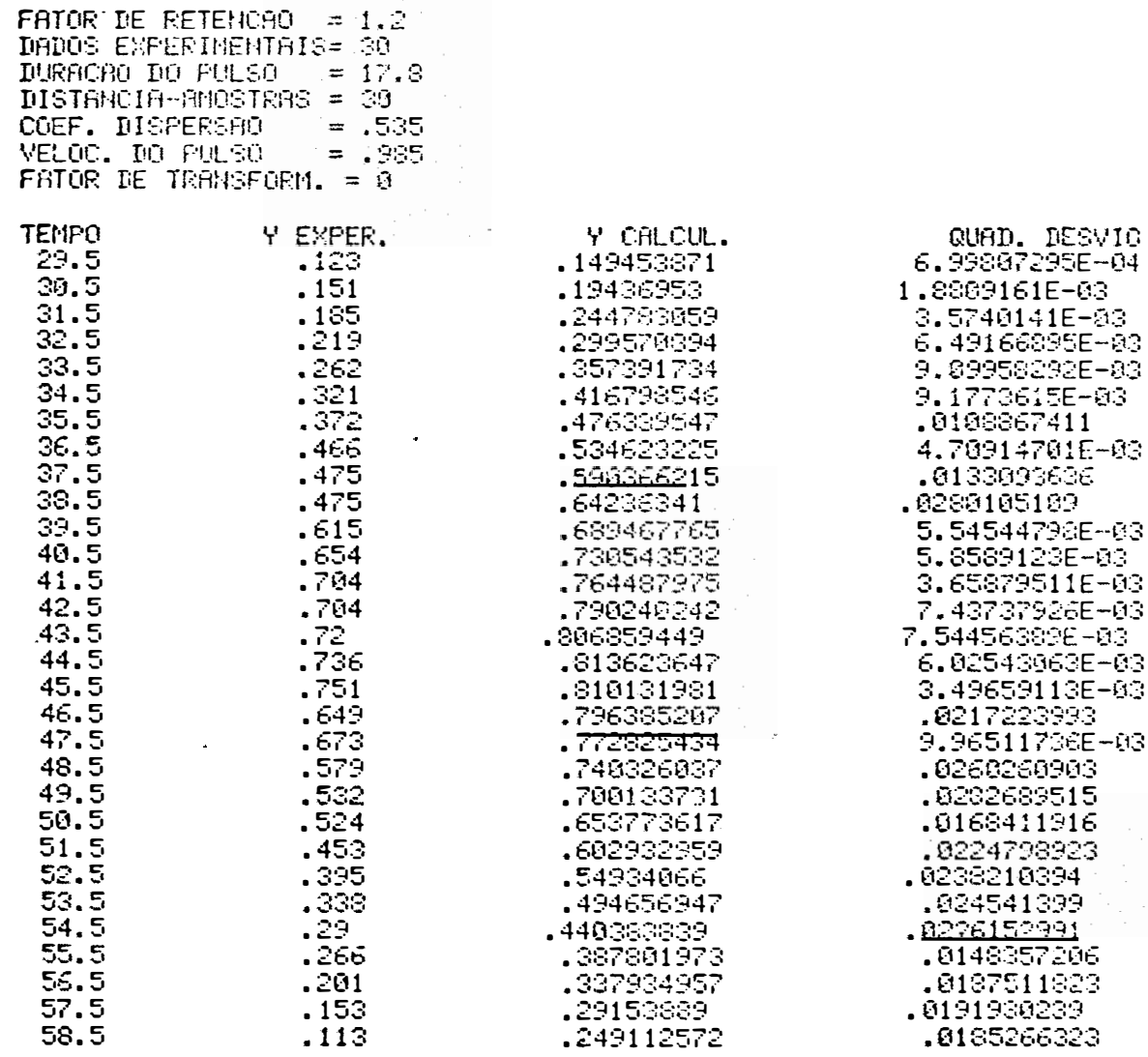

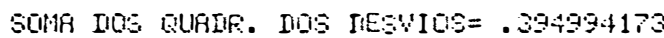

